\title{
3-D SPECTRAL INDUCED POLARIZATION (IP) IMAGING: NON-INVASIVE CHARACTERIZATION OF CONTAMINANT PLUMES
}

\author{
ANNUAL PROGRESS REPORT \\ for Period September 15, 1996-September 14, 1997
}

F. Dale Morgan, David P. Lesmes, William Rodi, Weiqun Shi, Kevin M. Frye, and John Sturrock

Earth Resources Laboratory

Department of Earth, Atmospheric, and Planetary Sciences

Massachusetts Institute of Technology

Cambridge, Massachusetts 02139

\section{December 1997}

\author{
Prepared for
}

THE U.S. DEPARTMENT OF ENERGY

AGREEMENT NO. DE-FG02-96ER14714

NOTICE: This report was prepared as an account of work sponsored by the United States Government. Neither the United States nor the Department of Energy, nor any of their employees, nor any of their contractors, subcontractors, or their employees, makes any warranty, express or implied. or assumes any legal liability or responsibility for the accuracy, completeness, or usefulness of any information, apparatus, product or process disclosed or represents that its use would not infringe privately-owned rights. 


\begin{abstract}
The objective of this project is to develop the scientific basis for characterizing contaminant plumes in the earth's subsurface using field measurements of induced polarization (IP) effects. Our first-year accomplishments are (1) laboratory experiments on fluid-saturated sandstones quantifying the dependence of spectral IP responses on solution chemistry and rock micro-geometry; (2) library research on the current understanding of electromagnetic coupling effects on IP data acquired in the field: and (3) development of prototype forward modeling and inversion algorithms for interpreting IP data in terms of 3-D models of complex resistivity.
\end{abstract}




\section{TABLE OF CONTENTS}

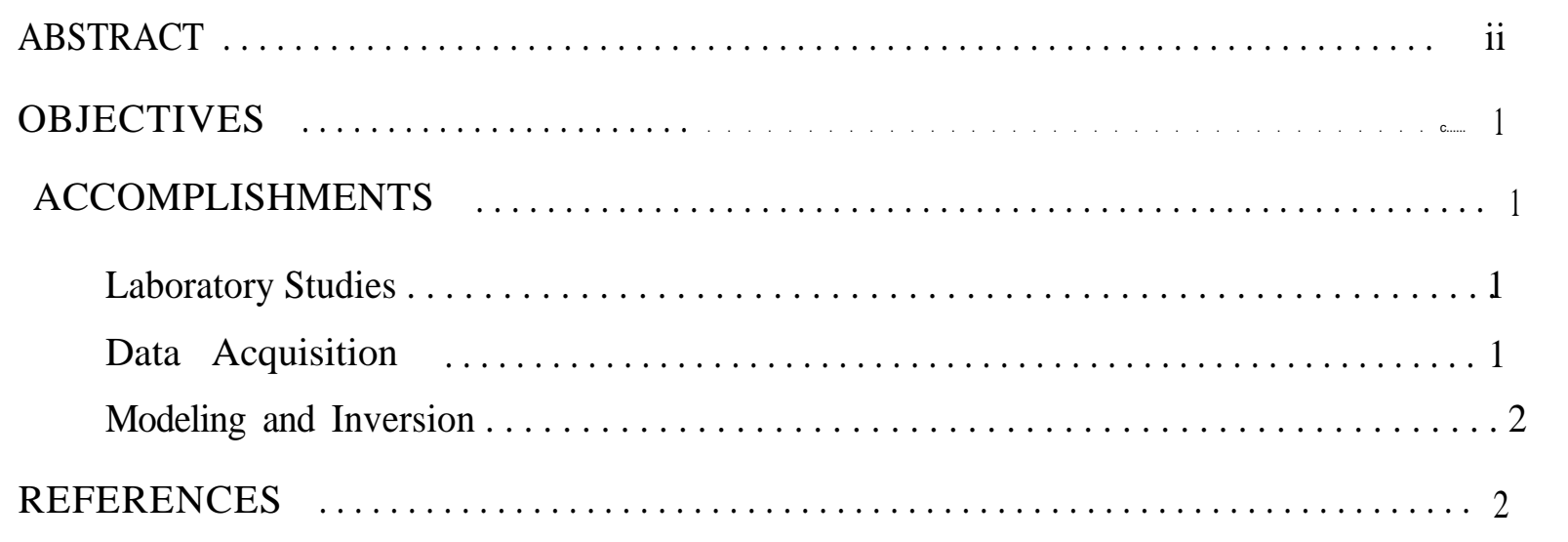

APPENDIX A: The Influence of Pore Fluid Chemistry on the Induced

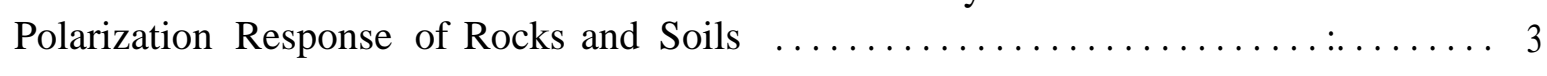

APPENDIX B: The Influence of Micro-Geometry on the Hydraulic Permeability and the Induced Polarization Response of Sandstones . . . . . . . . . . . . 13

APPENDIX C: 3-D Induced Polarization Inversion Using Complex Electrical Resistivities 


\section{OBJECTIVES}

The overall objective of this project is to develop the scientific basis for characterizing contaminant plumes in the earth's subsurface using field measurements of induced polarization (IP) effects. Three specific objectives towards this end are

1. Understanding IP at the laboratory level through measurements of complex resistivity as a function of frequency in rock and soil samples with varying pore geometries,. pore fluid conductivities and saturations, and contaminant chemistries and concentrations.

2. Developing effective data acquisition techniques for measuring the critical IP responses (time domain or frequency domain) in the field.

3. Developing modeling and inversion algorithms that permit the interpretation of field IP data in terms of subsurface geology and contaminant plume properties.

\section{ACCOMPLISHMENTS}

\section{Laboratory Studies}

Our laboratory experiments to date are described in Appendices A and B, which consist of two papers submitted to the annual SAGEEP conference (Frye et al., 1997; Sturrock et al., 1997). Our experiments involved measurements of complex resistivity vs. frequency on a suite of brine saturated sandstone samples. In one set of experiments. the fluid chemistry $(\mathrm{pH}$, ionic strength, and cation type) was varied. In a second set of experiments, the microgeometry of the rock matrix was varied. The experiments showed that spectral IP responses are sensitive to subtle variations in both the solution chemistry and rock microgeometry. The results demonstrate that spectral IP responses have the potential of being sensitive indicators of in situ chemistry and microgeometry, the latter of which may be related to the hydraulic properties.

\section{Data Acquisition}

We have been looking in some detail at the effects of electromagnetic coupling and how to practically deal with it. Currently, we do not have conclusive results. 


\section{Modeling and Inversion}

Our progress in the development of modeling and inversion algorithms for IP is described in Appendix C, a paper submitted to the annual SAGEEP conference (Shi et al., 1997). We have developed algorithms for forward modeling and inversion of spectral IP data in 3-D media. The algorithms accommodate. a general earth model with a complex electrical conductivity as a function of frequency and 3-D spatial position. Using regularization and optimization techniques. the inversion algorithm obtains a 3-D image of resistivity amplitude, and phase for each frequency contained in the data set. We have begun testing our algorithms on synthetic data generated from a simple model of a contaminant plume. The complex resistivity parameters of the background medium and plume are based on the laboratory results described above.

\section{REFERENCES}

Frye, KM., D.P. Lesmes, and F.D. Morgan, 1997, The influence of pore fluid chemistry on the induced polarization response of rocks and soils, submitted to SAGEEP annual meeting, Chicago, Illinois, Environmental and Engineering Geophysical Society.

Shi, W., W.L. Rodi, and F.D. Morgan, 1997, 3-D induced polarization inversion using complex electrical resistivities, submitted to SAGEEP annual meeting, Chicago, Illinois, Environmental and Engineering Geophysical Society.

Sturrock, J.T., D.P. Lesmes. and F.D. Morgan, 1997, The influence of micro-geometry on the hydraulic permeability and the induced polarization response of sandstones, submitted to SAGEEP annual meeting, Chicago, Illinois. Environmental and Engineering Geophysical Society. 


\title{
APPENDIX A
}

\section{THE INFLUENCE OF PORE FLUID CHEMISTY ON THE INDUCED POLARIZATION RESPONSE OF ROCKS AND SOILS}

\author{
Kevin M. Frye. David P. Lesmes \\ Boston College. Department of Geology and Geophysics \\ 140 Commonwealth Avenue. Chestnut Hill. MA 02167 \\ F. Dale Morgan \\ Earth Resources Laboratory, Department of Earth. Atmospheric and Planetary Science \\ Massachusetts Institute of Technology, 42 Carleton Street. Cambridge, MA 02142
}

\begin{abstract}
To improve containment detection and monitoring. it is important to understand the role of the bulk pore fluid chemistry on the induced polarization (IP) response of rocks and soils. IP methods can be more effective than traditional resistivity surveys because they are more sensitive to changes in electrochemistry at the mineral gram-pore fluid interface caused by small amounts of dissolved contaminant. Clean and contaminated materials have been shown to have comparatively different IP responses in both laboratory and field experiments. However. electrochemical surface properties are also dependent on the bulk pore fluid chemistry and grain microgeometry. The effect of contaminants on the IP response is superimposed upon these other bulk fluid and microgeometry effects.

To document the influence of pore fluid chemistry on the IP response of earth materials. experiments were performed to measure the complex conductivity and time domain IP of Berea sandstone cores as a function of pore fluid $\mathrm{pH}$, ionic strength, and cation type. A minimum in surface conductivity and IP response is observed at $\mathrm{pH} \mathrm{3.} \mathrm{the} \mathrm{approximate} \mathrm{point} \mathrm{of} \mathrm{zero} \mathrm{net}$ surface charge for quartz. While surface conductivity increases with ionic strength. the net IP response, or phase angle, decreases with ionic strength. A suite of cores saturated with different salt solutions of equal conductivity demonstrates significant variability in the IP response as a function of cation type. These experiments are applicable to other quartz-dominated systems and help to link field IP measurements to geochemical parameters. thus improving the IP characterization of geochemical environments.
\end{abstract}

\section{INTRODUCTION}

Groundwater contaminants often occur in small concentrations that do not significantly change the bulk conductivity of an earth material. IP methods are more sensitive to surface electrochemical processes than resistivity surveys and can detect the presence of some groundwater contaminants. Therefore. recent work has attempted to quantify the effect of both inorganic and organic contaminants on the induced polarization response of soils (Sadowski, 1988; Börner et al.. 1993). However. the IP response of a material is also dependent upon the properties of the bulk pore solution and grain microgeometry. To investigate the relationship between IP response of earth materials and pore fluid chemistry, core samples were taken from one block of Berea sandstone. The cores were saturated with various pore solutions and their response to an applied electric field was measured. 
The conduction current density $\mathbf{J}$ and the displacement current density $\mathrm{D}$ are related to the applied electric field $\mathrm{E}$ by the constitutive equations:

$$
\mathrm{J}=\sigma \mathrm{E}
$$

and

$$
\mathrm{D}=\mathrm{x} \varepsilon_{0} \mathrm{E} \text {, }
$$

where or is the permittivity of free space, $\mathrm{K}$ is relative permittivity, or dielectric constant, and is electrical conductivity. The system remains in the linear regime as long as the current density is less than $10^{-3} \mathrm{~A} / \mathrm{m}^{2}$ (Sumner, 1976). Electrical conductivity and dielectric constant can be expressed as complex numbers in the following manner:

$$
\sigma^{*}=\sigma^{\prime}+i \sigma^{\prime \prime}=\sigma^{\prime}+i \omega \kappa^{\prime} \varepsilon_{n}
$$

where $o^{\mathrm{i}}$ is the complex conductivity, and $\sigma^{\prime}$ and 0 " denote the real and imaginary components of conductivity, respectively, and $\mathrm{K}^{\prime}$ is the real component of complex relative permittivity, $\omega$ is the angular frequency of the applied electric field, and $i$ is fi. Complex resistivity is another common parameter used in electrical surveys and is the inverse of complex conductivity:

$$
\rho^{*}=\frac{1}{\sigma^{*}} \text {. }
$$

Generally. the complex resistivity, complex conductivity. and complex permittivity of an earth material are frequency dependent.

Frequency-domain IP methods measure electrical properties of a rock-pore fluid system at two or more frequencies. Some field measurements performed at only a few frequencies express IP phenomena as percent frequency effect (PFE) where the resistivity frequency dependence is expressed as follows:

$$
P F E=100 * \frac{\rho\left(\omega_{n}\right)-\rho\left(\omega_{1}\right)}{\rho\left(\omega_{0}\right)} .
$$

$\rho\left(\omega_{0}\right)$ and $\rho\left(\omega_{1}\right)$ are resistivity magnitudes measured at two different angular frequencies,

Time-Domain surveys measure the response of a sample to an applied electric field that is switched on and off. When an electric field is applied to a material, polarization occurs and a decay voltage is observed when the electric field is removed. The voltage decay curve is used to quantify polarization as integral chargeability, $\mathrm{M}$ :

$$
M=\frac{1}{V_{\text {max }}} \int_{t}^{t_{1}} V d t
$$

$\mathrm{V}$ is the potential difference across the sample. $\mathrm{V}_{\max }$ is the maximum potential difference during current transmission. and $\mathrm{t}_{1}$ and $\mathrm{t}_{0}$ define the time window over which potential difference is measured. We sampled the decay curve from 160 to 1740 milliseconds after the electric field was switched off.

In quartz dominated earth materials lacking metallic minerals, low frequency polarization occurs along the charged grain boundaries as counter-ions migrate around the grain. The counterions tend to arrange themselves into two layers, a fixed layer physically adsorbed to the grain surface. and a diffuse layer that extends into the pore space. When an electric field is applied to a material consisting of minerals, fluid, and their interface, movement of counter-ions tangential to the grain surfaces contributes to the real component of the formation conductivity. Depending on the frequency of the electric field, mobilitv of the ions, temperature, and grain microgeometry, the charges may polarize the grain to contribute to the imaginary component of conductivity. 
The distribution of charged sites on the surface of quartz grains, $\mathrm{SiOH}_{2}^{+}$and $\mathrm{SiO}$, is dependent upon the concentration of Hydrogen in the saturating solution. The $\mathrm{pH}$ at which an equal number of positive and negative sites exists (zero net surface charge) have been obtained theoretically for quartz (Glover et al., 1994) and experimentally for Berea sandstone (Li and De Bruyn, 1966, Sharma et al., 1987). All investigations have found that the net surface charge and the electrostatic potential at the fixed layer-diffuse layer interface (zeta potential, L), are zero in quartz and quartz dominated systems at pore fluid $\mathrm{pH}$ of approximately 3 (between 2 and 5).

\section{EXPERIMENTAL PROCEDURE}

Berea sandstone cores were cut and saturated with prepared brines in accordance with SCA guidelines (Lerner et al., 1990. Maeretat et al., 1990, Worthington et al., 1990). Three inch cores were placed in a four-electrode measurement system. Time-domain measurements of apparent resistivity and chargeability were performed. Chargeability was calculated from two voltage decay curves resulting from positive and negative current pulses. Impedance and phase measurements were performed In the frequency range of $10^{-3} \mathrm{~Hz}$ to $10^{3} \mathrm{~Hz}$. Higher frequency Impedance and phase measurements must be made with a two-electrode sample holder (Olhoeft 1985). Open and closed circuit compensations were performed with the sample holder connected to an HP 4284A LCR meter, and three lengths of core were measured. Real and imaginary components of Impedance were plotted versus sample length divided by sample crosssectional area. The slopes of the curves are equivalent to the real and imaginary components of resistivity (Lesmes, 1993).

\section{EXPERIMENTAL RESULTS}

\subsection{Complex Conductivity as a Function of Frequency}

In 1942, Archie proposed a model for conductivity in earth materials that was based on the assumption that nearly all conduction of electrical current in rocks and soils is electrolytic in nature, and therefore is a function of only pore fluid conductivity, porosity, saturation, and pore/grain geometry. From Archie's work comes the Formation Factor (FF) which is the ratio of solution conductivity to formation conductivity:

$$
F F=\frac{\sigma_{w}}{\sigma_{0}}
$$

If Archie's supposition holds, the Formation Factor should be a constant value for a given lithology. However, if other conduction mechanisms are present, the Formation Factor may vary with pore fluid chemistry. Because Formation Factor nomalizes for pore fluid conductivity, its variation represents pore fluid chemistry effects on the real component of surface conductivity in a straightforward manner. At low pore fluid conductivity, the contribution of surface conductivity lowers Formation Factor. With increasing pore fluid conductivity, Formation Factor approaches a constant value as electrolytic conduction in the pore fluid becomes dominant.

Low frequency dielectric dispersion is so large that it is difficult to demonstrate the subtle differences that occur as a function of pore fluid chemistry. The imaginary component of conductivity is graphed for low frequencies to demonstrate the dependence of polarization 
phenomena on pore fluid chemistrv. The imaginary component of conductivity demonstrates a frequency dependence. with a local maximum between $10^{-2}$ and $10^{-3} \mathrm{~Hz}$ that is similar for all samples. The local maximum is also present in other impedance spectroscopy studies of Berea sandstone (Lockner and Byerlee, 1985, and Lesmes, 1993). The variance in imaginary conductivity versus frequency plots may be due to the grain size distribution of Berea sandstone. The dielectric constant is plotted against frequency to show its high and low frequency limits.

The first data set presented shows the influence of $\mathrm{pH}$ on the complex conductivity of Berea sandstone cores saturated with a $10^{-2} \mathrm{M} \mathrm{NaCl}$ solutions with $\mathrm{pH}$ values of approximately 3, 5, 8, and 10 (FIG. 1). The Formation Factor varies from 8.6 to 14.6. The Formation Factor maximum at $\mathrm{pH} 3$ indicates that there Is a mmrmum in surface conductivity when cores are saturated with $\mathrm{pH} 3$ solutions. Minima also occur in the imaginary component of conductivity and dielectric constant at $\mathrm{pH} 3$.

The dielectric constant undergoes large low frequency dispersion. There are two critical changes in the slope of the dielectric constant versus frequency curves. At approximately $10^{-2}$ $\mathrm{Hz}$ the slope of the dielectric constant versus frequency plot changes, and the dielectric constant approaches its low frequency limit. Frequencies higher than $10^{5} \mathrm{~Hz}$ approach a constant dielectric constant. $\mathrm{E}_{\mathrm{d}}$, which obeys simple dielectric mixing laws for quartz and brine. The dispersion between the low frequency and high frequency dielectric constants are evidence of multiple polarization processes for all grain sizes present (Lesmes, 1993, Sturrock et. al., 1998).

By plotting the data with fixed $\mathrm{pH}$ 8. the dependence of complex conductivity on ionic strength can be observed. The plots represent the complex conductivity response of Berea sandstone cores saturated with solutions of $10^{-3} \mathrm{M}, 10^{-2} \mathrm{M}, 10^{-1} \mathrm{M}$, and $1 \mathrm{M} \mathrm{NaCl}$ (FIG. 2). Formation Factor is observed to have variability at $\mathrm{pH}$ 8: a dependence on ionic strength is observed as an increase in Formation Factor with $\mathrm{NaCl}$ molarity. At ionic strength above $10^{-1} \mathrm{M}$ $\mathrm{NaCl}$. Formation Factor nears a constant value and Archie's Law applies for Berea sandstone.

Dielectric constant Is presented for all frequencies measured. The range of dielectric dispersion at low frequencies masks the effect of pore fluid chemistry, but an increase with ionic strength is discernible in the imaginary component of conductivity plot. This effect is masked by the large increase in bulk conductivity, and the phase angles measured decrease with ionic strength. $1 \mathrm{M} \mathrm{NaCl}$ data is not included in these plots because the small phase angles measured approached the bit resolution of our low-frequency measurement system.

Cores were also saturated with different salt brines. The brines were prepared so that pore fluid conductivity was approximately the same for all cation type experiments, and $\mathrm{pH}$ was determined to be approximately 8 for all saturating solutions. These experiments are intended to show the effect of different cation types on adsorption and polarization properties (FIG. 3).

Formation Factor is observed to be approximately the same for the two monovalent cation solutions, $0.01 \mathrm{M} \mathrm{NaCl}$ and $0.084 \mathrm{M} \mathrm{KCl}$. The Formation Factor of the $0.064 \mathrm{M} \mathrm{CaCl}_{2}$ solution is considerably lower than that of the monovalent cation solutions, while the $0.096 \mathrm{M}$ $\mathrm{BaCl}_{2}$ solution is considerably higher. While the $\mathrm{BaCl}_{2}$ solution saturated cores do not behave in the same fashion as the $\mathrm{CaCl}_{2}$ solution saturated cores, previous work may provide an explanation. $\mathrm{Ba}^{++}$cations tend to adsorb chemically, rather than physically, to silica. and have been observed to reduce net surface charge density and zeta potential (Tadros and Lyklema, 1968). This could cause the higher Formation Factor measured in the $\mathrm{BaCl}_{2}$ saturated cores. 


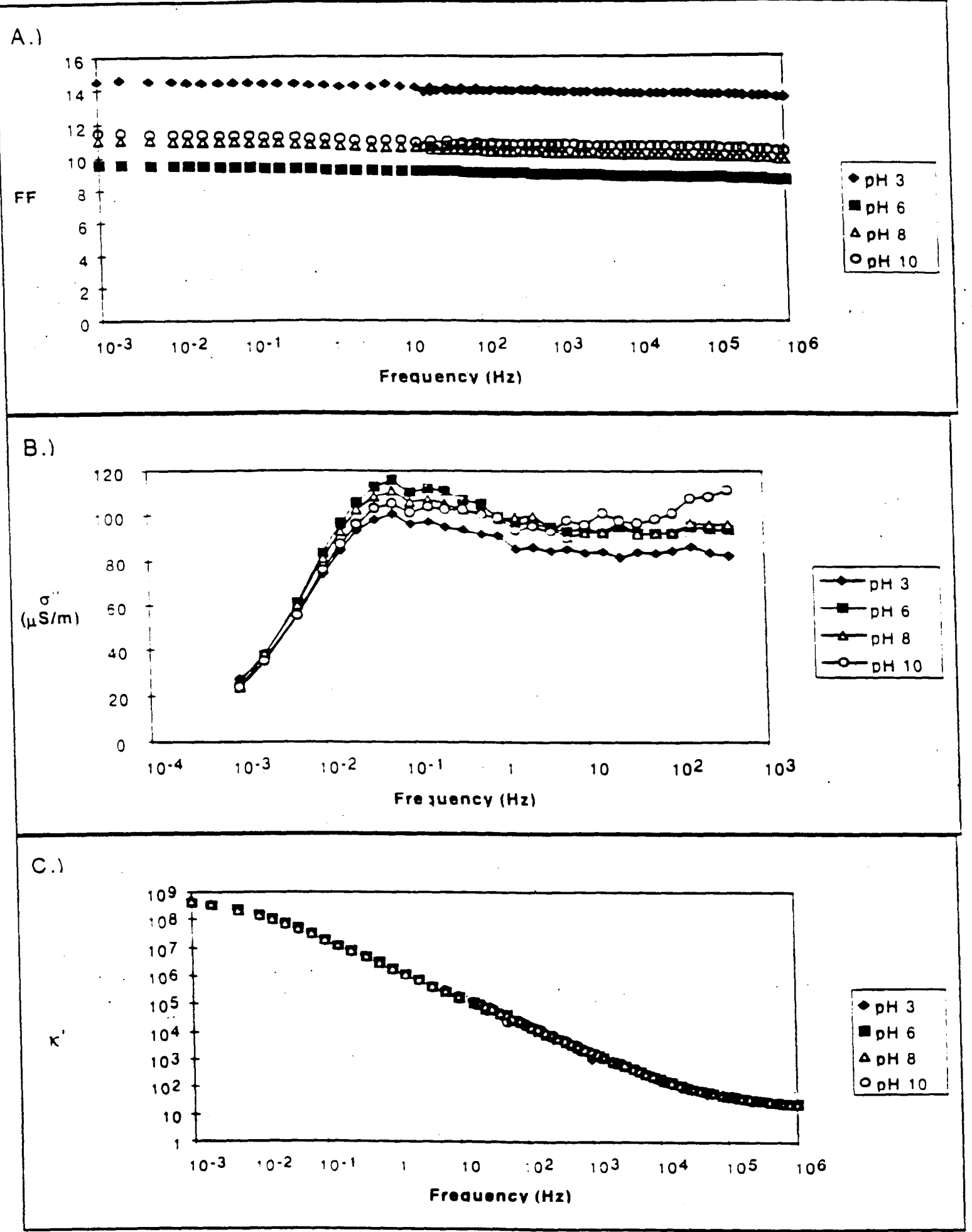

FIG. 1. Formation Factor (A), the imaginary component of conductivity (B), and dielectric constant (C) vs. frequency for Berea sandstone saturated with $10^{-2} \mathrm{M} \mathrm{NaCl}$ brines of $\mathrm{PH} \mathrm{3,6,8,} \mathrm{and} 10$. 


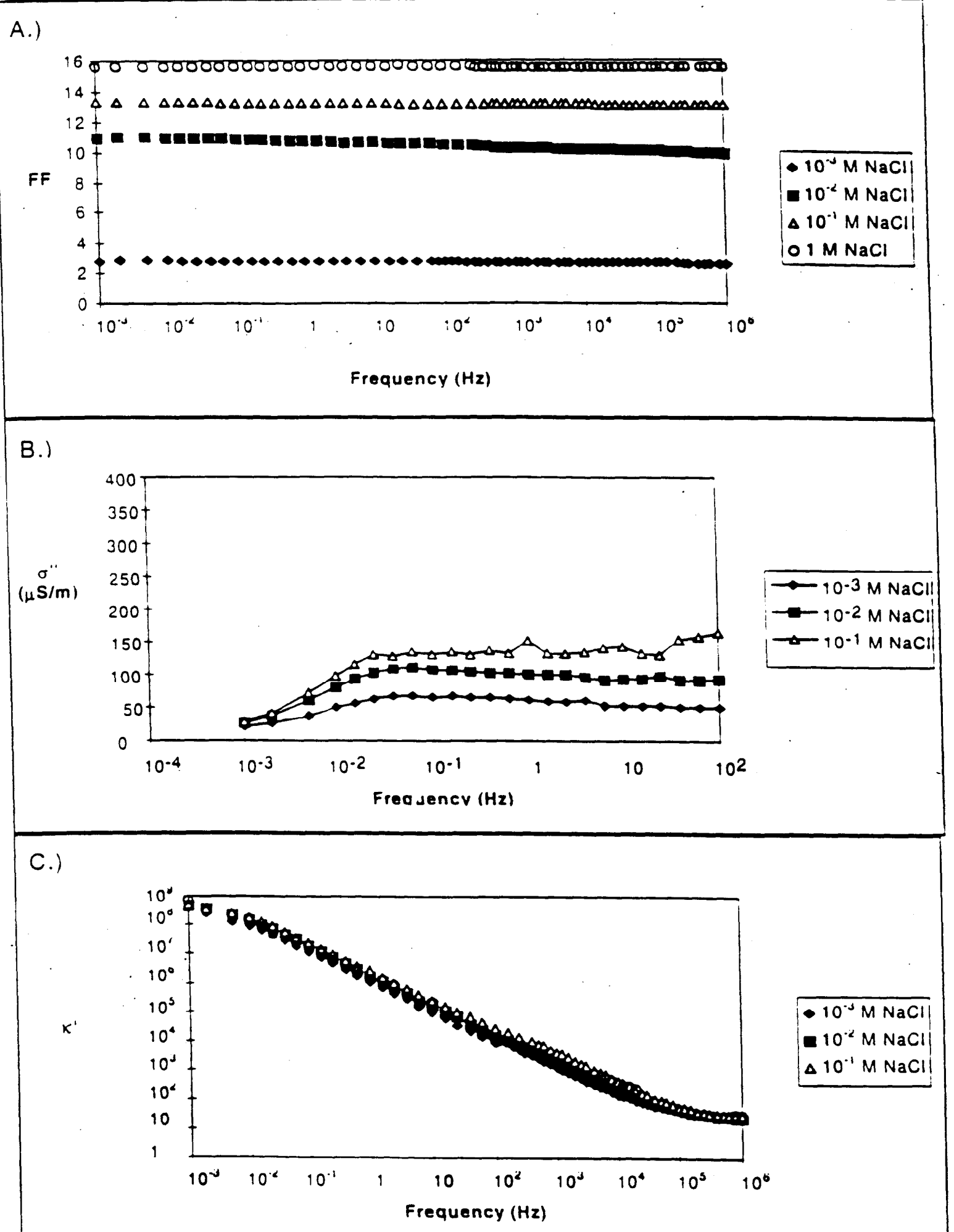

FIG. 2. Formation Factor (A), the imaginary component of conductivity (B), and dielectric constant (C) vs. frequency for Berea sandstone saturated with $10^{-3} \mathrm{NaCl}, 10^{-2} \mathrm{M} \mathrm{NaC} 1,10^{-1} \mathrm{M} \mathrm{NaCl}$, and $1 \mathrm{M} \mathrm{NaCl}$ brines of pH 8. 


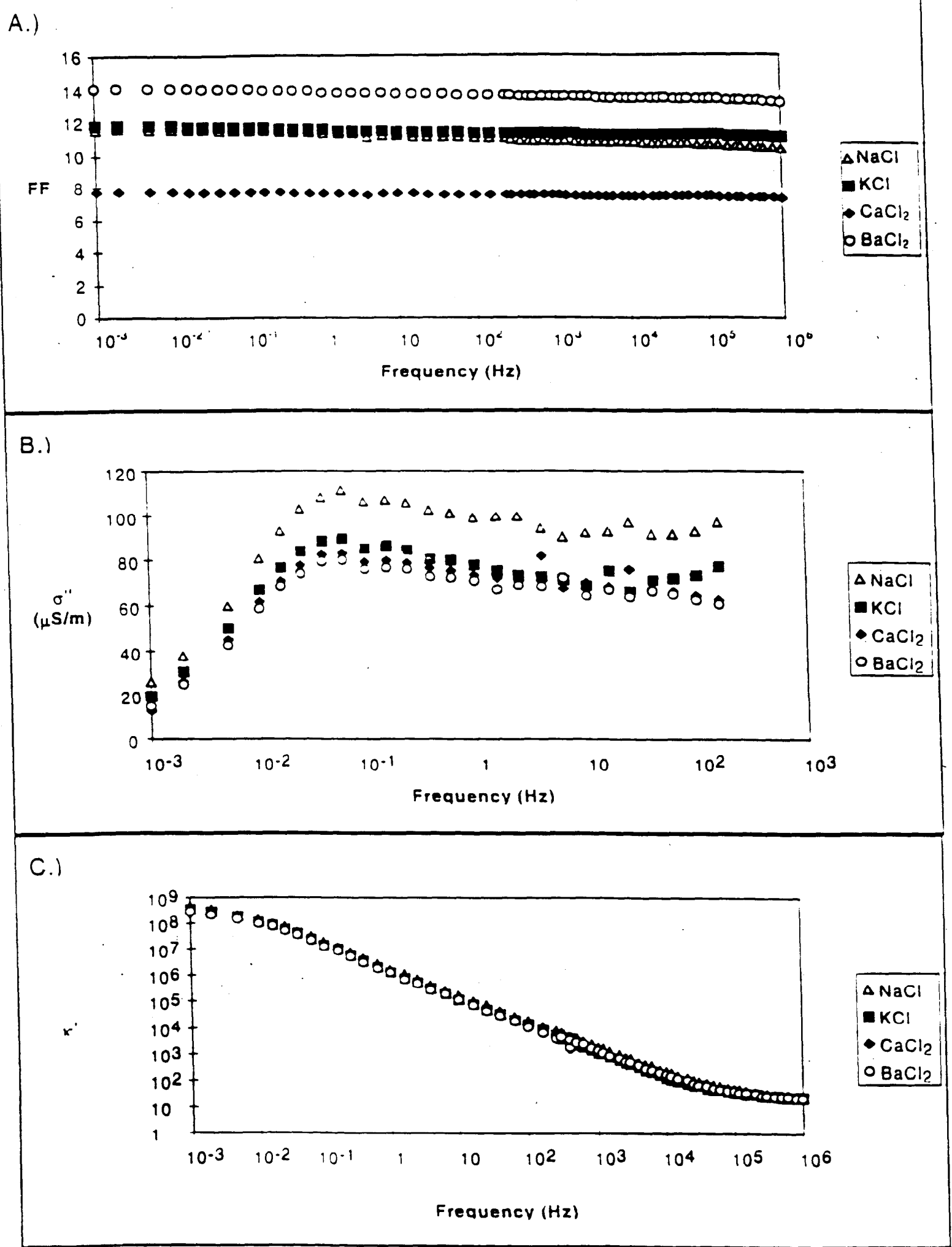

FIG. 5. Formation Factor (A), the imaginary component of conductivity (B), and dielectric constant (C) vs. frequency for Berea sandstone saturated with $10^{-2} \mathrm{M} \mathrm{NaCl}, 0.084 \mathrm{M} \mathrm{KCl}, 0.064 \mathrm{M} \mathrm{CaCl}_{2}$ and $0.096 \mathrm{M} \mathrm{BaCl}_{2}$ solutions. 
The low frequency imaginary conductivity indicates subtle changes in surface-chemistry. imaginary conductivity is highest in the $\mathrm{NaCl}$ saturated cores, and the $\mathrm{NaCl}$ saturated sample also displays the largest dispersion of the four experiments. The imaginary component of the $\mathrm{KCl}$ solution saturated core is less than that of the other monovalent salt, $\mathrm{NaCl}$. This effect could be the result of the smaller ionic radius of Potassium. The divalent metals, $\mathrm{Ca}^{++}$and $\mathrm{Ba}^{++}$, have similar imaginary conductivity curves. All samples appear to have the same tow frequency limit for imaginary conductivity and Dielectric Constant.

\subsection{Electrical properties as a function of pore fluid chemistry}

The following five electrical properties were chosen to summarize our experiments: average low frequency dielectric constant, average Formation Factor, high frequency dielectric constant, PFE and integral chargeability. The electrical properties are plotted versus brine conductivity for $\mathrm{NaCl}$ solutions of $\mathrm{pH} \mathrm{3,} \mathrm{6,} \mathrm{8,} \mathrm{and} 10$ (FIG. 4). Figure 4A demonstrates that Formation Factor increases with brine conductivity and approaches a constant value at high ionic strength $(0.1$ to $1 \mathrm{M} \mathrm{NaCl})$. Surface conductivity contributes less to the overall formation conductivity as ionic strength of the saturating brines increases, and Archie's Law becomes an accurate model of rock conductivity. Both low frequency and high frequency dielectric constant are observed to generally increase with brine conductivity (FIG. 4 B and C), indicating that the earth material is more polarizable. The influence of brine conductivity is similar at the different $\mathrm{pH}$ levels, but the effects are subdued at $\mathrm{pH}$ 3. The influence of surface conductivity is also observed in the PFE and M plots (FIG. 4 D and E). The plots demonstrate significant polarization effects at low brine conductivity which are masked at higher ionic strength in the frequency-domain and time-domain IP responses.

\section{SUMMARY}

Electrical properties of Berea sandstone were measured in the frequency-domain and the time-domain as a function of pore fluid $\mathrm{pH}$, ionic strength, and cation type. Imaginary conductivity and dielectric constant curves have similar shapes, regardless of pore fluid chemistry. The curve shape is perhaps influenced by the grain microgeometry. Although dielectric constant generally increases with ionic strength, increased polarization effects are masked by the higher overall bulk conductivity, and significant IP effects are not detected at ionic strength greater than $10^{-1} \mathrm{M} \mathrm{NaCl}$. A minimum in IP response is noticed in cores saturated with $\mathrm{pH} 3$ solutions. the approximate point of zero net surface charge for Berea sandstone. Variation of electrical properties with cation type is observed with different saturating salts. The causes of this variation are unclear, but it may be a function of both ionic valence and ionic radius. These bulk pore fluid chemistry effects are significant, and must be considered in interpreting Ip field data.

\section{ACKNOWLEDGMENTS}

Financial support for this paper was provided by Boston College and Department of Energy grant number: DE-FG07-96ER14714. 


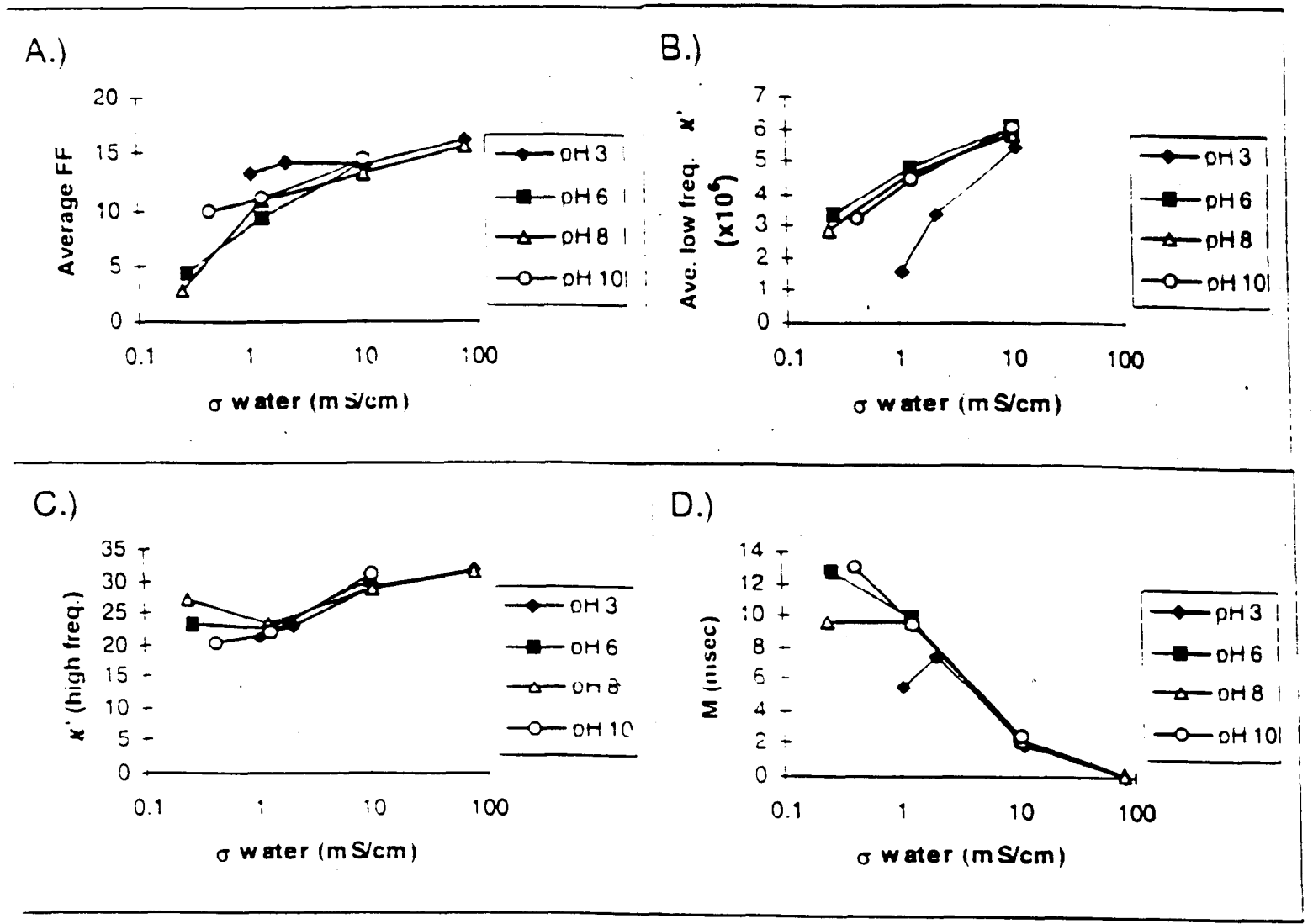

E.)

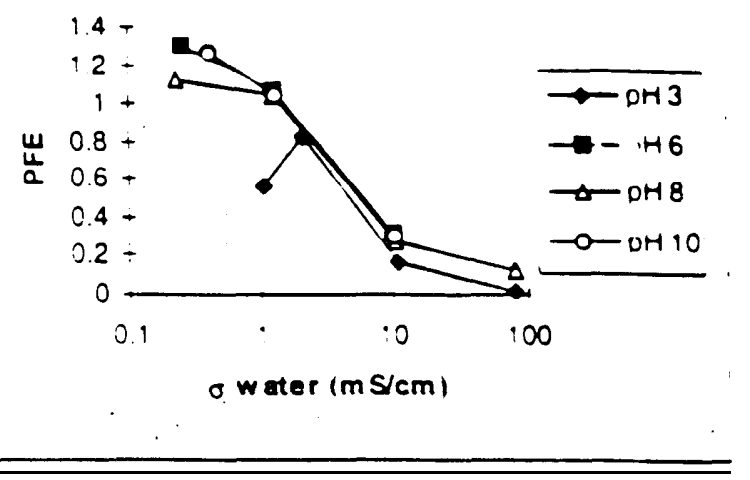

FIG. 4. Formation Factor (A), low-frequency dielectric constant (B), high frequency dielectric constant (C), chargeability (D), and percent frequency effect (E) of Berea sandstone as a function of brine conductivity and $\mathrm{pH}$.

\section{REFERENCES}

Archie G.E., 1942, The electrical resistivity $\log$ as an aid in determining some reservoir characteristics: Transactions of the American Institute of Mining, Metallurgical and Petroleum Engineers, 146, 54-62.

Börner, F., Gruhne, N., and Schon, J., 1993, Contamination indications derived from electrical properties in the low frequency range: Geophysical Prospecting, 41, 83-98. 
Glover, P. W. J,. Meredith P.G., Sammonds, P.R., and Murrell, S. A.F., 1994, Ionic surface electrical conductivity in sandstone: Journal of Geophysical Research, 99, 21635-2 1650.

Lerner, D.B., Dacy, J.M., Raible, C.J., Rathmeil, J.J., Swanson, G., Walls, J.D., 1990, SCA guidelines for sample preparation and porosity measurement of electrical resistivity samples: Part II--sample preparation and porosity measurement: the Log Analyst, 31, p. 57.

Lesmes, D.P., 1993, Electrical-impedance spectroscopy of sedimentary rocks: Ph.D. Thesis, Texas A\&M University.

Li, H.C. and DeBruyn, P.L., 1966, Electrokinetic and adsorption studies on quartz. Surface Science, 5, 203-220.

Lockner. D.A., and Byeriee, J.D., 1985, Complex resistivity of confined rock: Journal of Geophysical Research, 90, 7837-7847.

Maererat, N.L., Baldwin, B.A., Chaves, A. A., La Torraca, G.A., and Swanson. B.F., 1990, SCA guidelines for sample preparation and porosity measurement of electrical resistivity samples: Part IV--guidelines for saturating and desaturating core plugs during electrical resistivity measurements: The Log Analyst, 31, p. 68.

Olhoeft, G. R., 1985, Low-frequency electrical properties: Geophysics. 50, p. 2492-2503.

Sadowski, R.M., 1988, Clay-organic interactions: M.Sc. thesis. Colorado School of Mines.

Sharma, M. M., Kuo, J. F., and Yen, T. F., 1986, Further investigation of the surface charge properties of oxide surfaces in oil-bearing sands and sandstones. Journal of Colloid and Interface Science, 115, 9-16.

Sturrock, J. T., Lesmes, D. P., and Morgan, F. D., 1998, The effects of micro-geometry on the hydraulic conductivity and the complex conductivity response of sandstones: Symposium on the Application of Geophysics to Engineering and Environmental Problems, Conference Program, this Volume.

Sumner. J. S., 1976, Principles of Induced Polarization of Geophysical Exploration, Elsevier Science Publishing Co.

Tadros, Th. F. and Lyklema, J., 1968, The electrical double layer on silica in the presence of bivalent counter-ions, J. Electroanal. Chem., 22, 1-7.

Worthington, A.E., Hedges, J.H., and Pallatt, N., 1990, SCA guidelines for sample preparation and porosity measurement of electrical resistivity samples: Part I--guidelines for preparation of brine and determination of brine resistivity for use in electrical resistivity measurements: The Log Analyst, 31, p. 20. 


\begin{abstract}
APPENDIX B
THE INFLUENCE OF MICRO-GEOMETRY ON THE HYDRAULIC PERMEABILITY AND THE INDUCED POLARIZATION RESPONSE OF SANDSTONES

\author{
John T. Sturrock, David P. Lesmes \\ Boston College. Department of Geology and Geophysics \\ 130 Commomwealth Avenue, Chestnut Hill, MA 02167
}

F. Dale Morgan

Earth Resources Laboratory, Department of Earth, Atmospheric and Planetary Science Massachusetts Institute of Technology, 12 Carleton Street. Cambridge, MA 02142
\end{abstract}

\begin{abstract}
The transport properties of porous rocks and soils are of broad interest to many disciplines. An elusive goal in rock physics has been to develop a method of estimating permeability in-situ, and various models have been developed. These existing models characterize the porous media with parameters including porosity, hydraulic radius, grain packing. tortuosity, specific surface area, fractal surface dimension, grain size and grain size distribution. Induced polarization (IP) measurements are sensitive to many of the same variables associated with hydraulic permeability as well as with the pore fluid chemistry and may be able to measure the parameters which make up the permeability models

A series of experiments were performed on five different sandstones. Hydraulic permeability and broadband (spectral) induced polarization measurements were made on several sandstone samples both parallel and perpendicular to bedding. Interesting relationships are shown for the anisotropy data as a function of frequency. Porosity values were also determined for all of the sandstones. Permeability model parameters, including formation factor, porosity, specific surface area and surface fractal dimension were calculated using the IP data. Empirical models which relate the polarization capacitance of the sample to the grain size, surface fractal dimension and the specific surface area were investigated. The results indicate that the surface fractal dimension is the key component of the model and that the values determined from our experiments align extremely well with previously published data. Further investigation is being pursued in efforts to determine the fractal dimension solely from electrical measurements.
\end{abstract}

\title{
INTRODLCTION
}

Using Darcy's relationship, many researchers have developed methods of estimating permeability from the material properties which influence the percolation (or flow) through porous media. This relationship recognizes that the flow regime is linear. and hence it is a simplification of the Xavier-Stokes equation of fluid flow Darcy's law may be written as

$$
\mathrm{q}=-\frac{k}{\eta} \frac{d P}{d x}
$$


where $\mathrm{q}$ is the volume flow per cross sectional area (volume flux, $\mathrm{k}$ is permeability in units of length squared, $\eta$ is the dynamic viscosity and $\frac{d P}{d x}$ is the pressure gradient across the sample. Material properties which have been shown to affect permeability include the grain size and the grain size distribution, the porosity, the interconnectedness or tortuosity, of the pores and the specific internal surface area of the pore space Tube and crack models, for example, assume the medium can be effectively treated as a series of parallel tubes running through an impermeable matrix. An improvement of this simple model which incorporates tortuosity (the non-linear path of the fluid particles) leads to the Kozeny-Carman equation given by Scheidegger (1974) as

$$
k=\frac{\phi^{\vdots}}{5 S_{1 . . r}^{2}(1-\phi)^{2}} \text {. }
$$

where $\mathrm{k}$ is permeability in units of length squared. $\phi$ is the porosity and $\mathrm{S}_{\mathrm{por}}$ is the specific surface area to pore volume ratio (the area of the inside surfaces of the equivalent pores divided by the volume of the pores). The Kozeny-Carman relationship recognizes the hydraulic tortuosity $\tau_{\mathrm{h}}$ as being

$$
\tau_{h}=\frac{0}{k} \frac{A \pi}{8 \pi} .
$$

where $A_{\text {.ll }}$ is the effective cross sectional area of the pores (Scheidegger, 1974). The effective area is defined as $\pi r^{:} .$. or pi times the square of the hydraulic radius of the pore.

Spectral induced polarization, or complex impedance measurements made at multiple frequencies, is also determined by the same microgeometrical material properties that influence hydraulic flow as well as the pore fluid chemistry, and thus may contain the information needed to predict permeability. A fundamental empirical law, derived from electrical measurements which relates electrical conductivity to rock properties is known as Archie's law (1942), defined as

$$
\mathrm{F}=\phi^{-m}=\frac{\sigma}{\sigma}
$$

$\mathrm{F}$ is the formation factor, $\mathrm{m}$ is the cementation exponent (typically equal to two). $\sigma_{w, 1}$ is the electrical conductivity of the pore fluid and $\sigma_{\text {rixih }}$ is the bulk electrical conductivity of the rock and fluid system From this equation. the electrical tortuosity $\tau_{\mathrm{vi}}$ has been defined as $\varnothing \mathrm{F}$ (Scheidegger, 1974 ), $0 \mathrm{r}$

$$
\tau_{-1}=\phi F
$$

By equating the hydraulic tortuosity in equation (3) with the electrical tortuosity in (5). (5) Kozeny-Carman equation for hydraulic permeability, can be re-written as

$$
k=\frac{r^{2}}{8 \%}
$$

According to the tube and crack models. $S_{\text {pir }}$ is defined as the surface area of the tubes (pores) divided by the volume of the pores, or

$$
\mathrm{S}_{\text {mor }}=\frac{2 \pi . .1}{\pi \pi_{. . .}}=\frac{2}{r_{\text {. }}}
$$

This relationship assumes the pore surfaces to be smooth, or exactly two dimensional. However, due to weathering and cementation, or crystal growth on the grain structure, the specific surface area of the grains has been shown to be fractal. The surface fractal dimension has been determined for various sandstones by SEM (Scanning Electron Microscopy and BET (nitrogen 
adsorption) measurements, and the values range from 2.5 to 2.87 (Katz and Thompson. 1985; Krohn, 1988; Aharonov, Rothman and Thompson, 1997). From an empirical study on sandstones, Richardson (1961) determined the following scale dependent relationship:

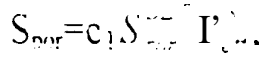

where the constant $c_{1}$ is $0.1410, S . ._{r}^{i}$ is the determination of $S_{\text {por }}$ from BET determinations (a limiting constant value measured at the molecular scale). $r_{\mathrm{eti}}$ is the hydraulic radius, and $\mathrm{s}$ (found

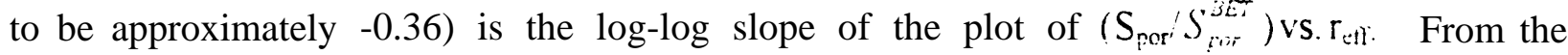
definition of a two-dimensional fractal, the surface fractal dimension is then calculated as $\mathrm{D}=2$-s. or 2.36 in this example Since $S_{m, r}$ can be written as $\frac{Z}{r}$. the Richardson relation reduces by substitution to

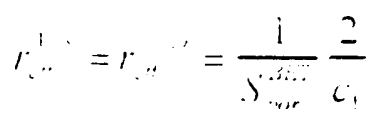

Substituting $r_{u ! 1}$ into the Kozeny-Carman equation thus produces the following result.

$$
\text { ShF }=c: i
$$

where $\mathrm{c}_{2}$ is a constant

This relationship, derived by Pape, Riepe and Schopper (1987), termed the PARIS equation, results from a pigeon-hole model investigation. It is otherwise written as

$$
k=\frac{\cdot,,) y y h 11}{1 .}
$$

From their empirical study, Pape, Riepe and Schopper determined $\mathrm{c}_{2}$ to be 475.337 and D to be 2.3566. Re-writing the equation thus produces

$$
k=475 \frac{. . . \cdots}{1:}
$$

Other investigators have also developed permeability models based on fractal studies Thompson. Katz and Krohn (1987) determined a similar relationship, given as

$$
k=\frac{1}{220} ; \frac{\sigma}{\sigma}=\frac{1}{226} \frac{\%^{\prime}}{\%} \text {. }
$$

where $i$ is the characteristic length of the tubes (pore space), $\sigma$ is the bulk rock conductivity and $\sigma_{\text {. }}$ is the ionic conductivity of the pore fluid. The characteristic length used in this model is similar to the development of the Richardson equation which relates length and hydraulic radius to the specific surface area used in the PARIS equation. These well constructed permeability models are quite similar, essentially varyingonly by a constant determined empirically from their studies. Our investigation builds on the PARIS mode 1 due to the possibility of estimating the specific surface area and fractal dimension directly from induced polarization measurements as explained below.

Rock fragments and clays have a surface charge due to weathering processes, where the dangling bonds have a net negative charge. This surface charge is $\mathrm{pH}$ dependent, depending on the ratio of $\mathrm{H}$ and $\mathrm{OH}^{-}$in solution. Above a $\mathrm{pH}$ of 3, which is typical of mostly all groundwater, the charge is negative. The attraction of ions in the saturating solution to the grain surfaces thus produces an electric double layer. When an electric field is applied to the sample, the imaginary 
part of the conductivity (phase related term) assuming an insignificant amount of metallic material in the grain matrix is a producer of the displacement current produced by the migration of the ions in the electric double layer on the surface of the grain. When using an A-C current source, the phase is thus attributed to the capacitance produced by the electric double layer ion migration. The real part of the conductivity is simply associated with the migration of ions through the fluid in the pore space.

The frequency dependence of the complex conductivity response for silicate rocks can be expressed with a power relationship Since the phase measured for silicate rocks between the frequencies $10^{-3} \mathrm{~Hz}$ to $10^{4} \mathrm{~Hz}$ is typically constant and the conductivity magnitude generally increases with increasingly frequency, the constant phase angle (CPA) model is given as

$$
\sigma^{*}(())=\sigma_{n}(i \omega)^{1 \cdot p} \text {. }
$$

according to Börner, Gruhne and Schon (1996), $\sigma^{*}((\cdot))$ is the measured complex conductivity as a function of frequency, $\sigma_{n}(i())$ is the "normalized" conductivity constant for the given set of data and 1-p is an exponent which describes the frequency dependence. The complex conductivity expression may then be split into the real and imaginary parts as shown:

$$
\sigma=\sigma \cos \left[\frac{\pi}{a}(1-\mu)\right] \text { and } \sigma^{\prime \prime}=\sigma \sin \left[\frac{\alpha}{a}(1-p)\right]
$$

The parameter $S_{n, 1}$ is the most difficult to measure non-invasively. Knight and Nur ( 1987) and Börner et al (I996) have recognized a linear relationship between $S_{p o r}$ on the imaginary part of conductivity. The relationship observed by Börner et al. (199 1) is given as follows:

$$
\mathrm{S}_{\mathrm{mir}}=\mathrm{a} \sigma^{\prime \prime} \text {. }
$$

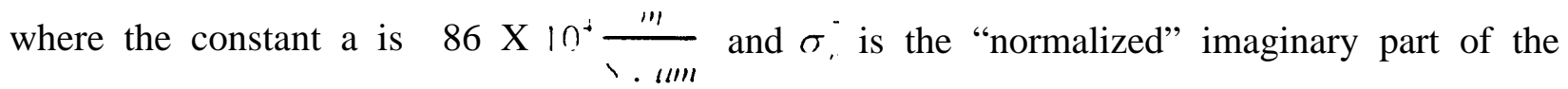
measured rock conductivity. Since $\sigma$ is produced by the displacement current which arises from the polarization of the electric double layer (EDL), it intuitively makes sense that it should be related to the specific surface area of the material Substituting (16) into the PARIS model yields

$$
\mathrm{k}=475 \frac{\left(\Delta \sigma_{.}\right)^{1+18}}{l}
$$

Thus, from electrical measurements alone it appears that the parameters which influence hydraulic, permeability may all be calculated, and that estimates of permeability may be made.

\section{EXPERIMENTAL PROCEDURE}

Complex impedance measurements were made in the frequency range of $10^{-3} \mathrm{~Hz}$ to $10^{4} \mathrm{~Hz}$ on five different sandstone samples cored both parallel and perpendicular to bedding. In an effort to isolate the microgeometry from the pore fluid chemistry, the saturating solution was fixed for all the samples by using a $0.01 \mathrm{M} \mathrm{NaCl}$ brine Two different apparatus were used to measure the samples' impedance and phase. In the low frequency range of $10^{-3} \mathrm{~Hz}$ to $10^{3} \mathrm{~Hz}$ a four electrode configuration was used. The higher frequency range of $20 \mathrm{~Hz}$ to $1 \mathrm{MHz}$ was measured with a two electrode apparatus, using an HP 4284A complex impedance analyzer. The high frequency measurements were made using pt-black electrodes and varying length samples. The pt-black 
electrodes were used to minimize the electrode impedance, and the samples of varying length were used to correct for residual electrode impedance effects and to estimate the measurement uncertainty. The overlap of frequencies between the two apparatus allowed direct comparison and validation of the two systems. Figure 1 shows the real and imaginary conductivity measurements made on Berea sandstone in the Boston College Rock Physics laboratory.

A modified constant-head test was used for all the hydraulic measurements.. The permeability measurements were made on the same sandstones cored both parallel and perpendicular to bedding. The permeability values for the different sandstones covered four orders of magnitude. The sandstones tested include Berea sandstone, Coconino sandstone, Tennessee sandstone, Arizona Chocolate and Island Rust sandstone.

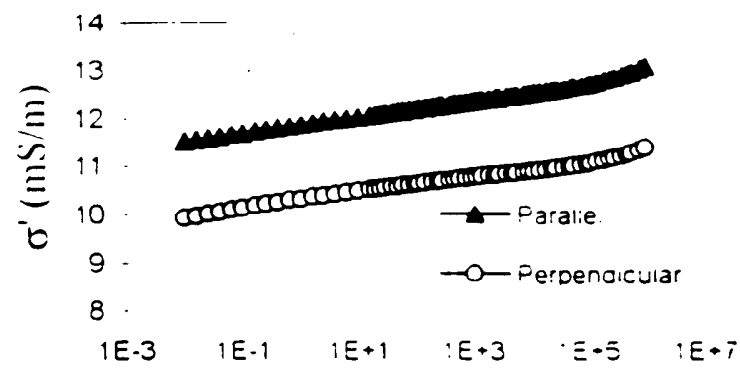

Frcquenci $(1+1)$

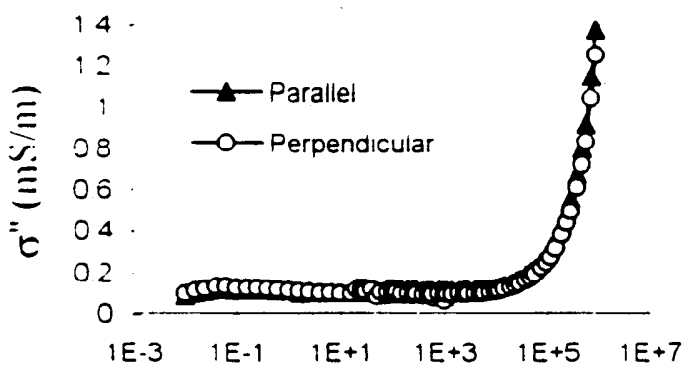

Frequencr $(\mathrm{H} /)$

FIG 1. Real and imaginary conductivity measurements made on Berea sandstone cores cut parallel and perpendicular to bedding.

\section{RESULTS}

The various parameters which make up the permeability models were measured and calculated from the induced polarization measurements. Using the hydraulic permeability measurements, the surface fractal dimension was also determined for the two bedding configurations of each of the sandstone. Table 1 shows the measured and predicted parameters for the suite of sandstones tested

The permeability values which were calculated solely from the electrical measurements, based on the PARIS model, did not result in accurate determinations Some calculations differed from the measured values by three orders of magnitude. The PARIS model uses the average surface fractal dimension of 2.36 based on Richardson's investigation, thus generalizations are made which unduly weight all other samples. This is seen here where the results of our calculations from this model yield permeability values which do not range beyond $10^{1}$ to $10^{2}$ millidarcies. 
Table 1. The permeability model parameters measured and predicted in the Boston (ollege Rock Physics laboratory.

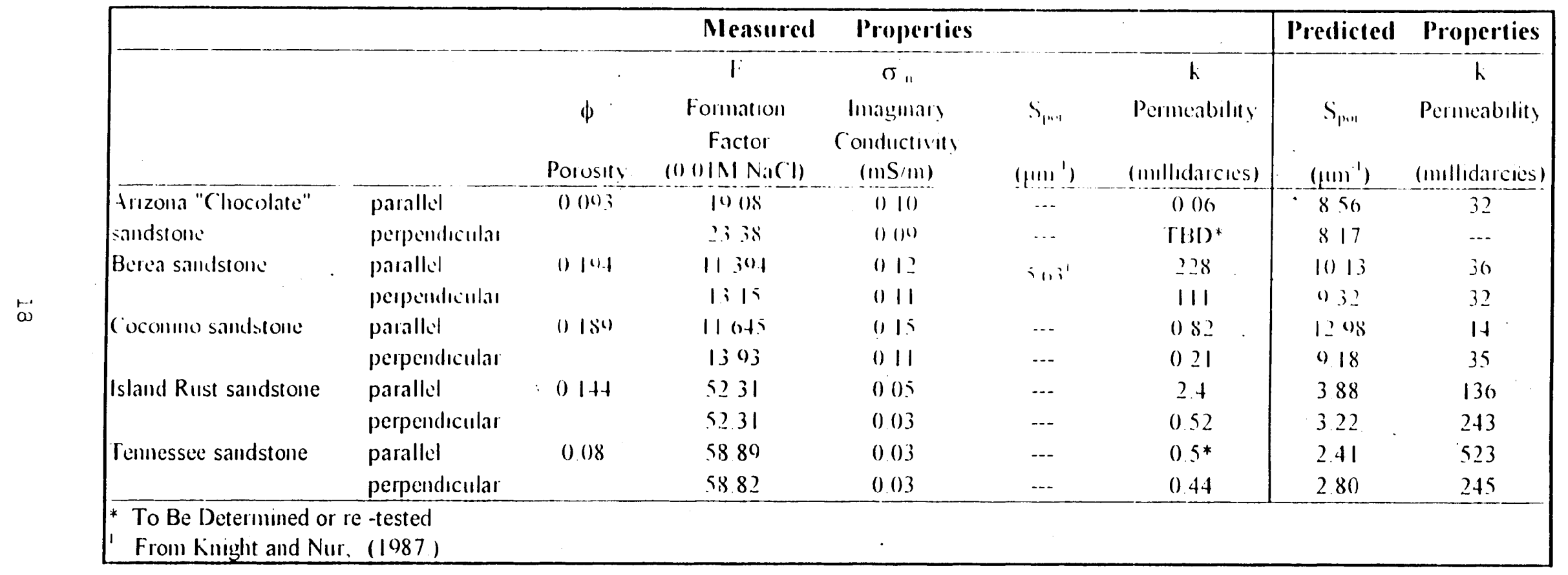


The surface fractal dimension was calculated (predicted) for each of the sandstones from the model using the hydro-electrically measured parameters. Table 2 shows the measured and the predicted values of surface fractal dimension. Simply re-substituting the calculated values back into the model would naturally yield accurate values of permeability. The calculated surface fractal dimension values for the different sandstones shown in Table 2 do not differ significantly; however, the differences do provide very different permeability estimations. This outcome follows fractal theory well, where power law dependent results are very sensitive to initial conditions. The fractal dimension values calculated from the hydraulic and electric measurements match up extremely well with previously published data. The surface fractal dimension values determined from our measurements are 2.55 (paralleland 2.57 (perpendicular) for the Berea sandstone, and 2.61 (parallel) and 2.73 (perpendicular) for the Coconino sandstone. Data presented by Katz and Thompson (1985) and Aharonov et. al. (1997) show the values for the same two sandstones to be 2.55 and 2.75 , respectively. This indicates the validity of the model and shows that if accurate values of the surface fractal dimension could be determined, reliable estimations of permeability could be made. Inversion of the complex electrical data for grain size distribution (Lesmes, 1993) has shown promise in determining the surface fractal dimension directly from the complex conductivity spectra.

The complex electrical measurements exhibit the sandstones' anisotropic nature and suggest that a great deal of information is contained therein. Figure 2 shows an interesting relationship for the Berea sandstone samples investigated. The plot displays the ratio of the measurements made parallel and perpendicular to bedding as a function of frequency for both the real and imaginary conductivities. The real part of the conductivity is essentially constant; however, the imaginary part of the conductivity which is related to the grain size, shape and sorting, shows an interesting frequency dependence Extracting information from this frequency dependent relationship will provide additional constraint to the existing geometrical models. All of the sandstones investigated have shown similar relationships and a further investigation is planned

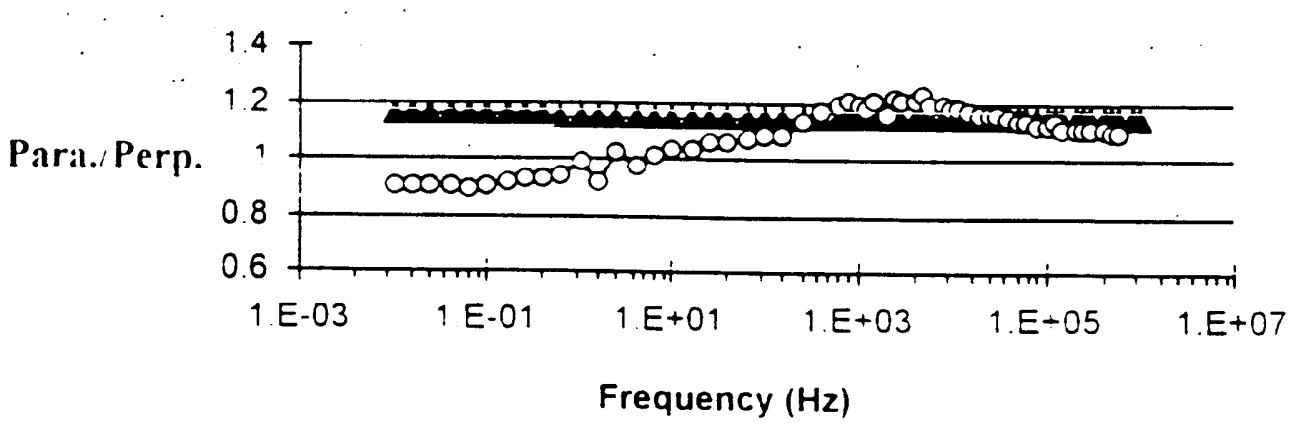

FIG 1 The complex conductivity anisotropy for Berea sandstone as a function of frequency. The filled triangles display the real conductivity and the open circles display the imaginary conductivity. 
Table 2 The measured and the predicted values surface fractal dimension (D)

\begin{tabular}{|llcc|} 
& & D & D \\
& & Measured & Predicted \\
\hline Arizona "Chocolate" & parallel & -- & 2.67 \\
sandstone & perpendicular & & $-\cdots-$ \\
Berea sandstone & parallel & $2.55^{*}$ & 2.55 \\
& perpendicular & & 2.57 \\
Coconino sandstone & parallel & $2.75^{*}$ & 2.61 \\
& perpendicular & $\ldots-$ & 2.73 \\
Island Rust sandstone & parallel & & 2.82 \\
& perpendicular & --- & 2.85 \\
Tennessee sandstone & parallel & & 2.84 \\
& p:rpendicular & 2.85 \\
\hline * Katz and Thompson. (1085) and Aharonov et. al. (1097.) \\
\hline
\end{tabular}

\section{SL'MMARY}

The electrical and hydraulic properties of several sandstones were measured using a fixed pore fluid chemistry to isolate the microgeometrical properties. An interesting relationship was observed for the anisotropic measurements made on the samples, and a further investigation is planned. It was shown that the surface fractal dimension is the key component of the permeability model used in this investigation. It was also demonstrated that the values determined in our experiments are in good agreement with previously published data. The ability to estimate the surface fractal dimension from induced polarization measurements would provide the final constraint for accurate estimates of permeability. Inversion of IP data for gain size distribution shows promise for calculating the surface fractal dimension and is being further investigated. As mentioned by Stanley Ward (1995), IP has a great deal of potential and will be an important tool in future investigations.

\section{ACKNOWLEDGMENTS}

This research was supported by the Boston College Department of Geology and Geophysics as well as by a grant from the U S Department of Energy. (DOE grant number DEFG07-96ER14714 )

\section{REFERENCES}

Aharonov, Einat, Daniel H Rothman and Arthur H Thompson, 1997. Transport Properties and Diagenesis in Sedimentary Rocks. The Role of Micro-Scale Geometry, Geology, 25, 547550 
Archie, G. E., 1942, The Electrical Resistivity Log as an Aid in Determining Some Reservoir Characteristics: Transactions of the American Institute of Mining, Metallurgical and Petroleum Engineers, 146, 54-62.

Börner. F D., J.R.Schopper and A. Weller, 1996, Evaluation of transport and storage properties in the soil and groundwater zone from induced polarization measurements: Geophysical Prospecting, 44, 583-601.

Börner, F.D. and Jürgen H. Schon, 1991, A Relation Between the Quadrature Component of Electrical Conductivity and the Specific Surface Area of Sedimentary Rocks: The Log Analyst, 32, 612-613.

Katz, A. J. and A. H. Thompson, 1985, Fractal Sandstone Pores: Implications for Conductivity and Pore Formation, Physical Review Letters, 54. 1325-1328.

Knight, Rosemary J. and Amos Nur, 1987, The Dielectric Constant of Sandstones, $60 \mathrm{kHz}$ to 4 MHz, Geophysics, May, 644-651.

Krohn, Christine E., 1988, Fractal Measurements of Sandstones. Shales. and Carbonates, Journal of Geophysical Research, 93, 3297-3305.

Lesmes, David P., 1993, Electrical Impedance Spectroscopy of Sedimentary Rocks: Ph.D. Dissertation, Texas A\&M University.

Pape, Hansgeorg, Lutz Riepe and Jurgen R. Schopper, 1987, Theory of Self-Similar Network Structures in Sedimentary and Igneous Rocks and Their Investigation with Microscopical and Physical Methods, Journal of Microscopy, 148, 121- 147.

Richardson, L. F., 1961, The Problem of Contiguity: An Appendix to Statistics of Deadly Quarrels General Systems Yearbook, 6, 139-187

Scheidegger, Adrian E., 1973, The Physics of Flow through Porous Media. Toronto: University of Toronto Press.

Thompson, A. H., A. J. Katz and C. E. Krohn, 1987, The Microgeometry and Transport Properties of Sedimentary Rock, Advances in Physics, 36, 625-694.

Ward, Stanley H., Ben K. Sternberg, Douglas J. LaBrecque and Mary M. Poulton, Recommendations for IP Research,The Leading Edge, April 1995, 243-247. 


\title{
APPENDIX C
}

\section{3-D Induced Polarization Inversion using Complex Electrical Resistivities}

\author{
Weiqun Shi, William Rodi, and F. Dale Morgan \\ Earth Resources Laboratory \\ Dept. of Earth, Atmospheric, and Planetary Sciences \\ Massachusetts Institute of Technology \\ 42 Carleton Street \\ Cambridge, MA 02142 \\ Tel:(617)253-7868 \\ Fax:(617)253-6385 \\ Email:shi@erl.mit.edu
}

\begin{abstract}
A B S T RACT
Induced polarization (IP) is a current-stimulated electrical phenomenon observed as a delayed voltage response in earth materials. The basic mechanism of the IP response is mainly driven by electrochemical processes. It has been indicated that the IP method is an effective means of detecting and mapping environmental contaminants in many situations where conventional d.c. resistivity has been ineffective. In this paper we present an inversion technique for interpreting frequency-domain IP data in terms of complex electrical resistivity in the subsurface. The amplitude of the observed voltage and its phase shift from the injected current are inverted to recover a 3-D subsurface resistivity structure. Extended from a 3-D d.c. resistivity inversion technique, the algorithm uses the complex bi-conjugate gradient method in both the forward modeling and inversion. The IP inversion procedure we have developed can be applied to 1-D, 2-D, or 3-D earth models and to any configuration of current and potential electrodes. We illustrate our methods by inverting synthetic data taken over a contaminated plume embedded in a homogeneous background medium. The model parameters are based on laboratory measurements.
\end{abstract}

\section{INTRODUCTION}

The most common electrical method used in exploration geophysics measures only the steady state, or d.c., electrical response of the subsurface. However, some earth materials possess an effective reactance which is observed as a time-delayed voltage response to an electric current source. This induced polarization (IP) effect is caused by electrochemical processes at the boundaries of metallic grains or at fluid/rock interfaces. It has been suggested that the IP method is an effective means of detecting and mapping groundwater contaminants in many situations where d.c. resistivity has been ineffective. Excellent reviews on the IP method and case histories can be found in Sumner (1976), Fink et al (1990), Bertin and Loeb (1976), and Madden and Cantwell (1967).

Surveying with the IP method is in principle similar to d.c. resistivity: measuring potential difference between two points on the surface of the earth or in bore hole. However, interpretation of IP data is considerably more complex. In the interpretation of IP data. most authors adopt a method given by Siegel (1959) that the ultimate effect of a chargeable body alters its effective conductivity. As such, the IP and DC resistivity problems are intimately linked, and the inversion of IP data is a two-step process (Oldenburg and Li, 1994). In the first step, the DC potentials are inverted to recover the background conductivity $\sigma_{b}$. The second step recovers the perturbed 
conductivity so that a chargeability can be recovered. This procedure may be suited for the forward modeling problem but for the inversion it is not practical because of the measurement inaccuracy and errors in numerical computation which result in instabilities in the inversion procedure.

In this paper, we present an alternate IP inversion technique base on the frequency domain measurements. This technique is based on the assumption that the resistivity value of subsurface is complex. Complex resistivity results in a complex electrical potential observed on the surface of the earth and recorded as the amplitude of the electrode potential and the phase shift from the injected current signal. A general algorithm to simulate the response of an arbitrary 2-D or 3-D distribution of complex resistivity to arbitrary arrays of current and receiver electrodes and its inversion procedure are then developed.

\section{THEORY}

The induced polarization phenomenon is usually modeled macroscopically as a generalization of Ohm's law in which voltage $\mathrm{V}(\mathrm{t})$ is linearly related to current $\mathrm{I}(\mathrm{t})$ through convolution with an impedance response function $\mathrm{R}(\mathrm{t})$ :

$$
V(t)=\int_{0}^{\infty} R\left(t^{\prime}\right) I\left(t-t^{\prime}\right) d t^{\prime}
$$

Treating the earth as a continuum. We have at each point

$$
\mathbf{E}(t)=\int_{0}^{\infty} \rho\left(t^{\prime}\right) \mathbf{J}\left(t-t^{\prime}\right) d t^{\prime} .
$$

where $\mathrm{E}$ is the electric field, $\mathrm{J}$ is the current density, and $\rho$ is the electrical resistivity. The function $\rho(t)$ is taken as the superposition of an instantaneous response and a decaying memory function. We write this as

$$
\rho(t)=\rho_{0}\left[\left(1-\eta_{0}\right) \delta(t)-\frac{d}{d t} \eta(t)\right]
$$

where $\rho_{0}$ is the d.c. resistivity. $\eta_{0}$ is the total chargeability, and $\eta(t)$ is a decay function. $\eta_{0}$ is a number between zero and one: the function $\eta$ is equal to $\eta_{0}$ for $t \leq 0$ and decays to zero as $t \rightarrow \infty$. The Fourier transform of $\mathrm{p}(\mathrm{t})$ defines a complex resistivity as a function of frequency, $\mathrm{p}(\mathrm{w})$, such that

$$
\mathbf{E}(\omega)=\rho(\omega) \mathbf{J}(\omega)
$$

For low frequencies. electromagnetic induction can be ignored and $\mathrm{E}$ is the gradient of a potential field $V$ that is determined by the current conservation law

$$
\nabla \cdot\left(\frac{1}{\rho(\mathbf{x}, \omega)} \nabla V(\mathbf{x} \cdot \omega)\right)=-I(\mathbf{x} \cdot \omega)
$$

where I is the source current. In the IP method, the difference between $V$ at two point electrodes is measured, as generated by a source (I) comprising current injected at two other electrodes. In the time-domain method, the current is a transient signal obtained by shutting a steady current and $\mathrm{V}$ is sampled as a function of time. In the frequency-domain method, I is harmonic and the amplitude and phase lag of $V$ is measured for a set of source frequencies. The inverse problem is to use such measurements, for many different current and potential field electrode locations, to infer the complex resistivity function $\rho\left(\mathrm{x}, \boldsymbol{\nu}^{\prime}\right)$ or, alternatively, the d.c. resistivity function $\rho_{0}(\mathbf{x})$ and chargeability function $\eta(\mathbf{x} . t)$. 
The inversion method of $\mathrm{Li}$ and Oldenburg (1994) uses time-domain IP data to infer two parameters of the medium as a function of position: the d.c. resistivity, $\rho_{0}(\mathbf{x})$, and total chargeability, $\eta_{0}(\mathrm{x})$. Yuval and Oldenburg (1997) extended the time-domain approach by using samples of the potential fields $V$ at discrete times, $t_{k}$, to infer $\rho_{0}(\mathbf{x})$ and $\eta\left(\mathbf{x}, t_{k}\right)$. (They fit the sampled medium response at each point $\mathrm{x}$ with Cole-Cole parameters as an additional step.) In this paper we develop a frequency-domain approach. Complex potential field measurements at discrete frequencies, $\omega_{k}$, are used to infer the complex resistivity in the earth at these same frequencies, $\rho\left(\mathbf{x}, \omega_{k}\right)$.

\section{Forward Modeling}

Given a complex resistivity function $\rho$, the predicted IP response of the earth for a given source $I$ and frequency $\omega$ is obtained by solving equation (5) (with suitable boundary conditions). IP data are samples of $V$ at various electrode locations. It is clear that the forward problem separates with respect to w, i.e. the IP data for a particular frequency depends on the earth's resistivity only at that frequency.

We solve (5) numerically using the transmission network method developed by Madden (1972). This method, like finite differences, entails sampling $\rho$ and $V$ spatially on a dense, 3-D grid and then solving a linear system of equations.

$$
\kappa v=s,
$$

Where $K$ is a matrix depending on the resistivity function $\rho$ and grid geometry; $\mathrm{v}$ is a vector containing the potential field samples at grid points; and $\mathrm{s}$ is a source vector determined by integrating the current distribution I over grid elements. The resulting equations are precisely those for d.c. resistivity modeling but with $K, v$ and $\mathrm{s}$ complex, instead of real, quantities. The matrix $K$ is complex symmetric, not Hermitian.

We solve the system (6) using a complex bi-conjugate gradient method (e.g. Jacob, 1986). Given that $K$ is symmetric, the bi-conjugate gradient method reduces to a special form which is very similar to the (real) conjugate gradient method extended to complex numbers. Although the bi-conjugate gradient method for complex symmetric systems is not guaranteed to converge (Jacob, 1986), our experience to date has not encountered convergence problems, owing probably to the fact that for the types of earth materials we have considered, the imaginary part of $\rho$, and hence $K$ and $\mathrm{v}$, are much smaller than its real part.

\section{Inverse Problem in the Frequency Domain}

Let us define a complex vector $d_{k}$ to contain all the complex potential measurements associated with a fixed frequency $\omega_{k}$. Each component of $d_{k}$ corresponds to a single source and receiver electrode configuration. We let $m$ denote a model function that defines the complex resistivity in the subsurface as function of position and frequency. In this paper, we use

$$
m(\mathbf{x} \cdot \omega)=\log \rho(\mathbf{x} \cdot \omega) .
$$

Therefore, the real part of $m$ is the log amplitude of the complex resistivity (log IpI) while the imaginary part of $m$ is the phase of resistivity.

We may state the frequency-domain, IP inverse problem then as determining the function $m$ from the equations

$$
d_{k}=G\left(m: \omega_{k}\right)+e_{k}, \quad k=1,2 \ldots n
$$


where $\mathrm{G}$ represents the forward modeling operator, defined implicitly by equation (5), and each $e_{k}$ is a (complex) error vector. In this paper we do not address the interpolation of $m$ with respect to $\omega$ via parameterization (e.g., Cole-Cole) or smoothing. Instead, since the forward problem separates by frequency, we approach (8) as $n$ separate inverse problems with the objective of inferring $\mathrm{m}$ only at the observation frequencies, $\omega_{k}$. That is, we solve

$$
d_{k}=G\left(m_{k}\right)+e_{k}, \quad k=1,2, \ldots n
$$

where $m \&(x)=m\left(\mathbf{x}, \omega_{k}\right)$. (Note that. if the source is independent of frequency, G does not depend explicitly on $\mathrm{w}$.

\section{INVERSION ALGORITHM}

Our inversion algorithm solves the inverse problem for each frequency $\omega_{k}$ separately. Accordingly, in this section we drop the subscript $k$ on the data vector $d$ and model function $\mathrm{m}$.

The IP inverse problem (for a given frequency) is ill-posed because $\mathrm{m}$ is a function of continuous position while $d$ is finite-dimensional. In practice. $m$ is sampled on a grid and is thus finitedimensional, but the grid is intentionally dense and the ill-posed nature of the problem remains. To obtain stable solutions of the inverse problem we employ the method of Tikhonov regularization, following the implementation of Shi et al (1996) for d.c. resistivity inversion. That is, we define solutions in terms of an optimization problem where an objective function, $\Psi(m)$, is minimized. We write $\Psi$ as

$$
\begin{aligned}
\Psi(m) & =\|d-G(m)\|^{2}+\tau\|L m\|^{2} \\
& =(d-G(m))^{H}(d-G(m))+\tau m^{H} L^{T} L m
\end{aligned}
$$

where $H$ denotes the conjugate transpose, or Hermitian, $L$ is a linear operator taken to be the Laplacian $\left(L=\nabla^{2}\right.$, so $\left.L^{H}=L^{T}\right)$, and $\tau$ is a positive number (the "regularization parameter"). The first term of $\Psi$ is the chi-squared measure of the data misfit. The second term defines the *stabilizing functional" of Tikhonov's method.

The objective function $\mathrm{k}$ defined above presumes that the real and imaginary parts of $d$ have independent errors sharing the same variance matrix. Further, a common smoothness constraint is applied to the real and imaginary parts of $\mathrm{m}$. We discuss this special case of our inversion algorithm here for convenience, but note that, in practice, it is more realistic to weight the real and imaginary parts of both $d$ and $\mathrm{m}$ differently.

Since the forward modeling operator $G$ depends nonlinearly on $\mathrm{m}, \Psi$ in (10) is not a quadratic functional and an iterative or search algorithm is needed to find its minimum. A commonly used iterative method is the Gauss-Newton method. It starts with an initial guess, $m_{o}$, and at the kth iteration step finds a model $m^{k+1}$ that minimizes an approximate version of $\Psi$, defined by linearizing $\mathrm{G}$ at the current model, $m_{k}$

$$
G\left(m^{k}+\delta m\right)=G\left(m^{k}\right)+A \delta m
$$

where $\mathrm{A}$ is the complex sensitivity matrix defined as

$$
A=A_{r}+i A_{i}
$$

with

$$
A_{r}=\frac{\partial G_{r}}{\partial m_{r}}=\frac{\partial G_{i}}{\partial m_{i}}
$$




$$
A_{i}=-\frac{\partial G_{r}}{\partial m_{i}}=\frac{\partial G_{i}}{\partial m_{r}}
$$

are both real quantities.

Substituting (11)-(14) into (10) we obtain

$$
\begin{aligned}
\Psi\left(m^{k}+\delta m\right) & =\left(d-G\left(m^{k}\right)-. A \delta m\right)^{H}\left(d-G\left(m^{k}\right)-A \delta m\right)+\tau\left(m^{k}+\delta m\right)^{H} L^{T} L\left(m^{k}+\delta m\right) \\
& =\text { Minimun }
\end{aligned}
$$

Let

$$
\delta m=\delta m_{r}+i \delta m_{i}
$$

Then $\Psi\left(m^{k}+\delta m\right)=$ minimum requires

$$
\begin{aligned}
\frac{\partial \Psi}{\partial \delta m_{r}}= & -2 A_{r}^{T}\left[d_{r}-G_{r}\left(m^{k}\right)\right]-2 A_{i}^{T}\left[d_{i}-G_{i}\left(m^{k}\right)\right]+2 \tau L^{T} L m^{k}+ \\
& 2\left(A_{r}^{T} A_{r}+A_{i}^{T} A_{i}+\tau L^{T} L\right) \delta m_{r} \\
= & \operatorname{Re}\left\{-2 A^{H}\left[d-G\left(m^{k}\right)\right]\right\}+2 \tau L^{T} L m^{k}+2\left(A_{\tau}^{T} A_{r}+A_{i}^{T} A_{i}+\tau L^{T} L\right) \delta m_{\tau}=0 \\
\frac{\partial \Psi}{\partial \delta m_{i}}= & \operatorname{Im}\left\{-2 A^{H}\left[d-G\left(m^{k}\right)\right]\right\}+2\left(A_{\tau}^{T} A_{r}+A_{i}^{T} A_{i}+\tau L^{T} L\right) \delta m_{i}=0
\end{aligned}
$$

Putting them together

$$
\left(A^{H} A+\tau L^{T} L\right)\left(\delta m_{r}+i \delta m_{i}\right)=\operatorname{Re}\left\{A^{H}\left[d-G\left(m^{k}\right)\right]\right\}+\tau L^{T} L m+i \operatorname{Im}\left\{A^{H}\left[d-G\left(m^{k}\right)\right]\right\}
$$

i.e.

$$
\left(A^{H} A+\tau L^{T} L\right) \delta m=A^{H}\left[d-G\left(m^{k}\right)\right]+\tau L^{T} L m
$$

We solve this equation by complex bi-conjugate gradient method. Since $\left(A^{H} A+\tau L^{T} L\right)$ on the left hand side of this equation is Hermitian matrix, the complex bi-conjugate gradient method becomes the general conjugate gradient with the complex form, as one would expected.

The Gauss-Newton method thus constructs a sequence of the models by

$$
m^{k+1}=m^{k}+\delta m
$$

\section{SYNTHETIC EXAMPLE}

We have inverted a synthetic IP data computed from a single plume model in Figure 1. The model consists of a 70x70x40 meter plume embedded in a homogeneous background. The complex resistivity parameters of the background medium are based on laboratory data from Berea sandstone cores saturated with $0.01 \mathrm{M} \mathrm{NaCl}$ solution with $\mathrm{pH}$ value of 8 , while data from $0.01 \mathrm{M} \mathrm{BaCl}_{2}$ solution saturated cores are used to determine the contamination plume parameters. The laboratory measurements used are from Frye, et al (1998). The model parameters we used are shown in Table 1. The IP data responses are simulated on a $5 \times 5$ electrode array and comprise 24 potential measurements for each of 9 current sources at frequency $f=1(\mathrm{~Hz})$ and $f=100(\mathrm{~Hz})$, respectively.

The inversion results are shown in Figure 2-4. The inversion results depict the plume in both amplitude and phase frames. The frequency dependence of the plume resistivity is clearly detected and is comparable to the "true" model's frequency response. Although in this example we only considered IP response at two single frequencies, the inversion method is general and by repeating the inversion procedure we can obtain a more complete complex electrical properties of the sample over a large frequency band. 


\begin{tabular}{|c|c|c|c|}
\hline Sample Material & Frequency $(\mathrm{Hz})$ & Amplitude $(F . m)$ & Phase (mrad) \\
\hline Berea Sandstone $+\mathrm{NaCl}$ & 1 & 11815.37 & -7.698 \\
\hline Berea Sandstone $+\mathrm{NaCl}$ & 100 & 11577.85 & -7.100 \\
\hline Berea Sandstone $+\mathrm{BaCl} 2$ & 1 & 10164.005 & -4.779 \\
\hline Berea Sandstone $+\mathrm{BaCl} 2$ & 100 & 10027.040 & -4.163 \\
\hline
\end{tabular}

Table 1: Complex resistivity parameters of the model

\section{CONCLUSIONS}

We have developed algorithms for forward modeling and inversion of spectral IP data in 3-D media. The algorithms accommodate a general earth model with a complex electrical resistivity as a function of frequency and 3-D spatial position. Regularization and optimization techniques are employed to obtain stable solutions to the nonlinear inverse problem. We have successfully applied our inversion technique to synthetic data from a known model, demonstrating the feasibility of interpreting spectral IP data directly in the frequency domain.

\section{ACKNOWLEDGMENTS}

This work was supported by the U.S. Department of Energy, Office of Energy Research, under grant number DE-FG07-96ER14714.

\section{REFERENCES}

Bertin, J., and Loeb, J., 1976, Experimental and aspects of induced polarization, Vol. 1 and 2, Gerbruder Borntraege.

Fink, J. B., McAlister, E. O., Sternberg, B. K., Wieduwilt, W. G., and Ward, S. H., 1990, Induced polarization: applications and case histories: Investigations in Geophysics No. 4, SEG

Frye, K.M., Lesmes, D. P. and Morgan F. D., 1998, The influence of pore fluid chemistry on the induced polarization response of rocks and soils, Proc. SAGEEP'98, submitted.

Jacobs, D.A., 1986. A generalization of the conjugate gradient method to solve complex systems, IMA J. Sum. Analysis, 6, 447-452.

Madden. T. R.. and Cantwell. T., 1967: Induced polarization, a review, in Mining Geophysics, 2, Theory: Soc. Exp. Geophys., 46, 916-931.

Oldenburg, D. W., and Li, Y., 1994, Inversion of Induced Polarization Data, Geophysics, Vol. 59, 1327-1341.

Siegel, H. O., 1959, Mathematica1 formulation and type curves for induced polarization. Geophysics, Vol. 24, 517-565.

Shi, W.W., Rodi, R.L. Mackie and J. Zhang, 1996, 3-D dc electrical resistivity inversion with application to a contamination site in the Aberjona Watershed. Pтoc. SAGEEP'96, 1257-1267.

Sumner. J. S., 1976, Principles of induced polarization for geophysical exploration, Elsevier, Amsterdam.

Weller, A., Seichtcr M., and Kampke, A., 1996, Induced-polarization modeling using complex electrical conductivity, Geophys. J. Int., 127, 387-398.

Yuval, and Oldenburg D. W., 1997, Computation of Cole-Cole parameters from IP data, Geophysics, Vol. 62, 436-448. 


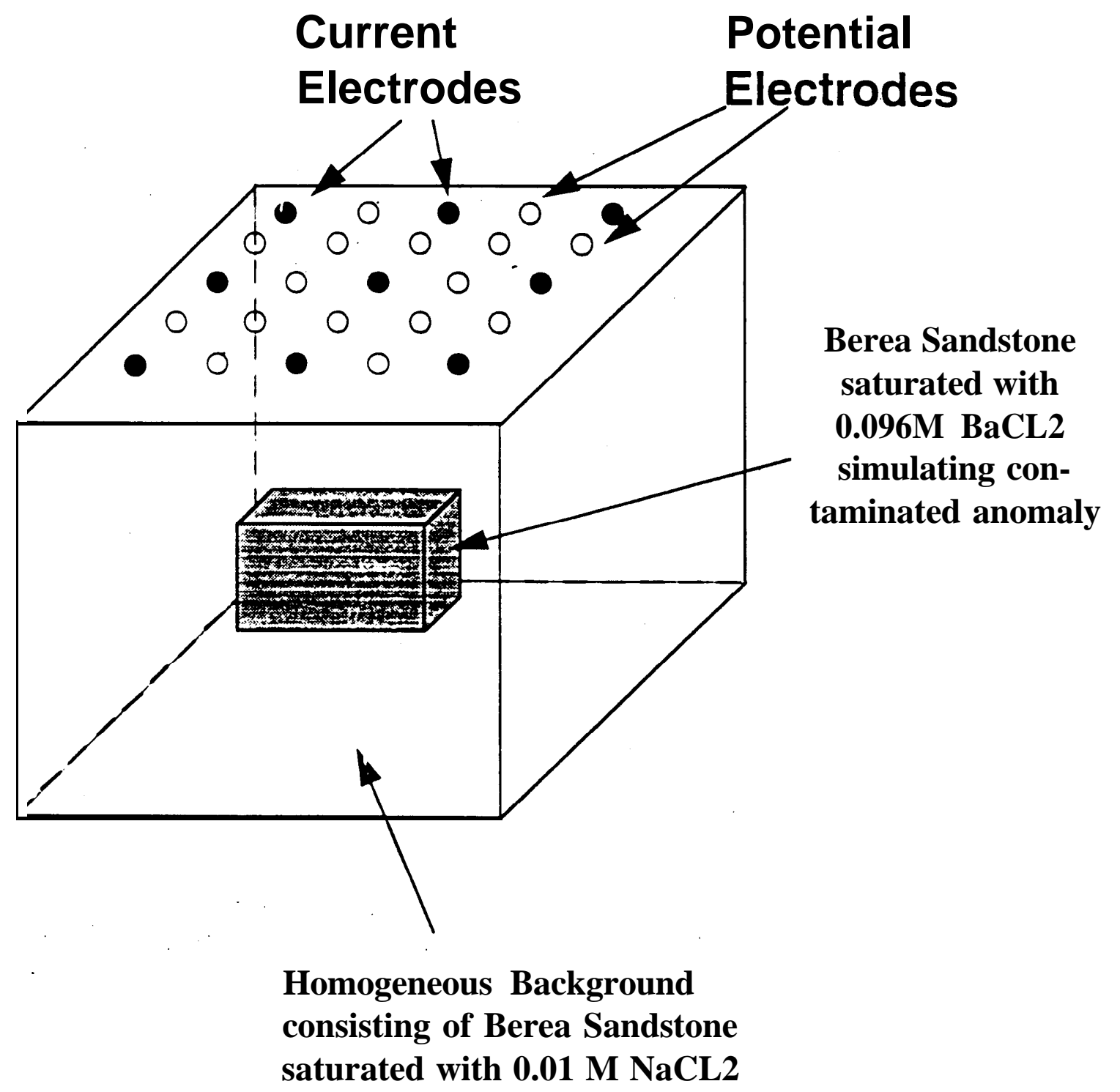

Figure 1. Simple model of a contaminated plume embedded in a homogeneous background. The complex resistivity parameters as a function of frequency are based on the laboratory results. Synthetic IP data were computed for the electrode array at the surface. 

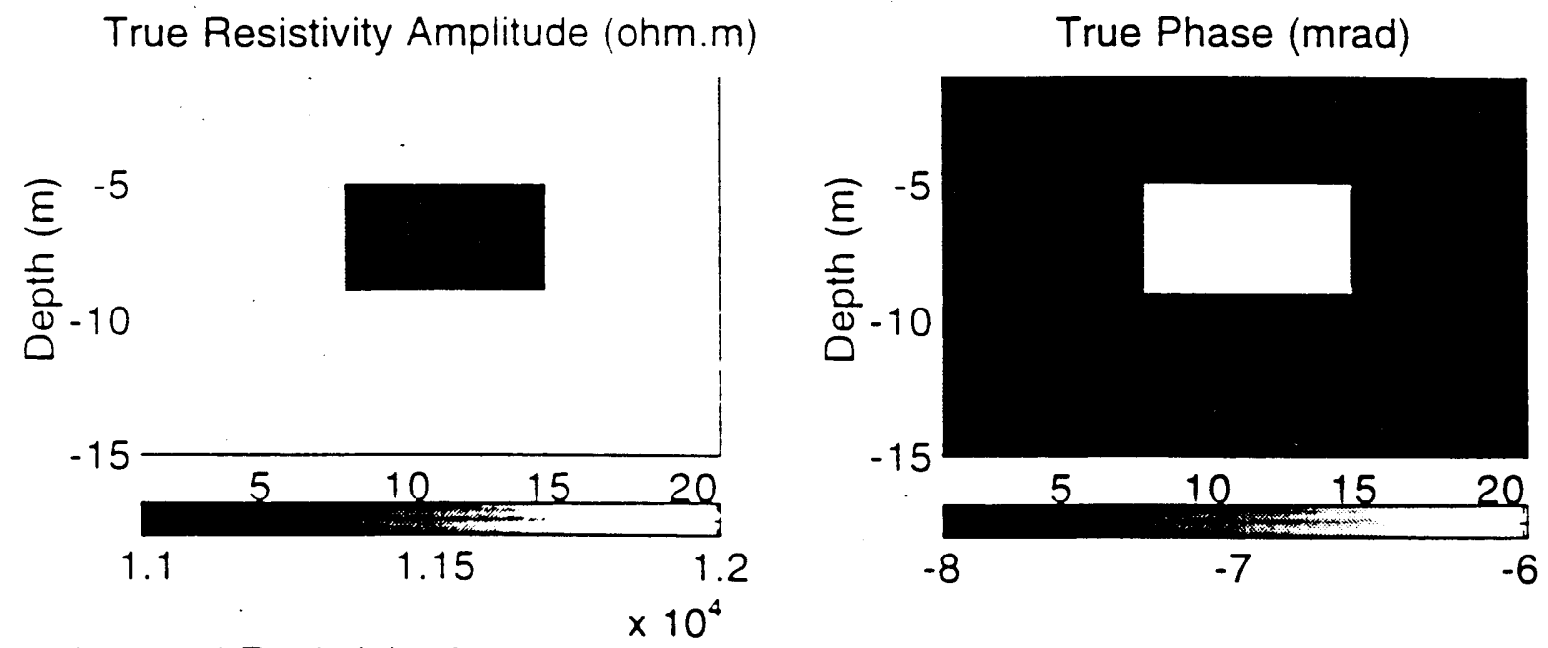

Inverted Resistivity Amplitude (ohm.m)

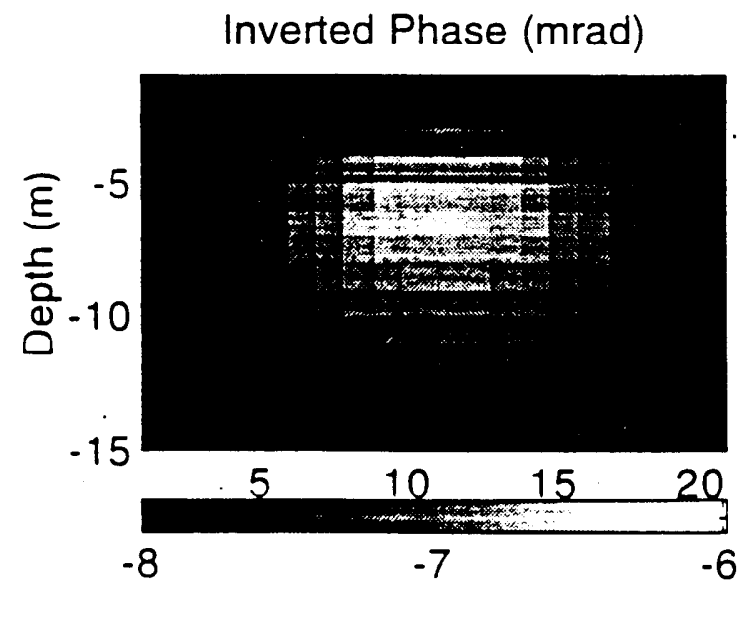

Figure 2 Inversion images for $\mathrm{f}=1 \mathrm{~Hz}$ (bottom) are compared to the "true" model (top). Each frame shows a cross-section through the center of the 3-D model. The amplitude of the complex resistivity is shown on the left, and the phase is shown on the right. 

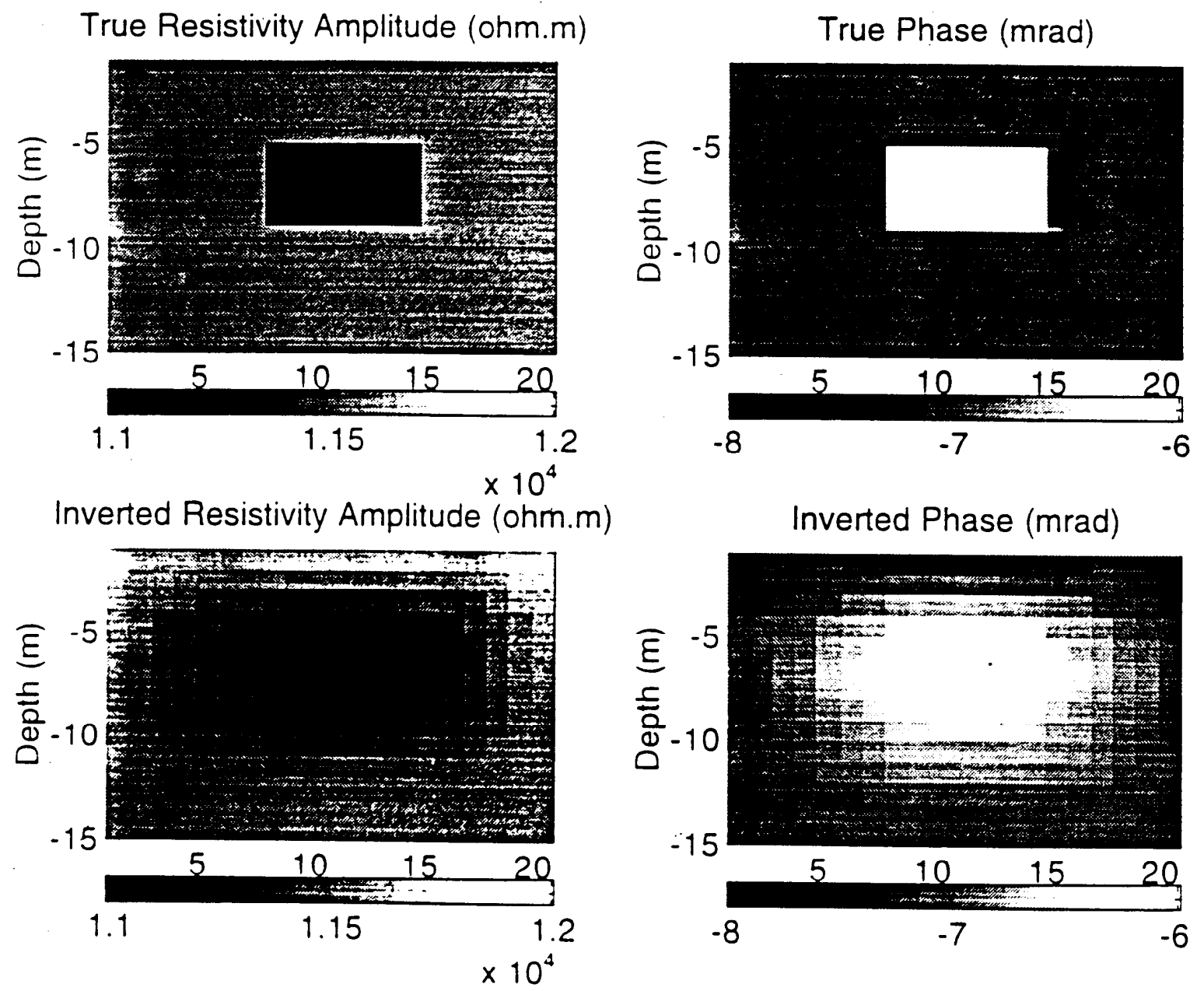

Figure 3. Same as Fig.4 for $\mathrm{f}=100 \mathrm{~Hz}$. 

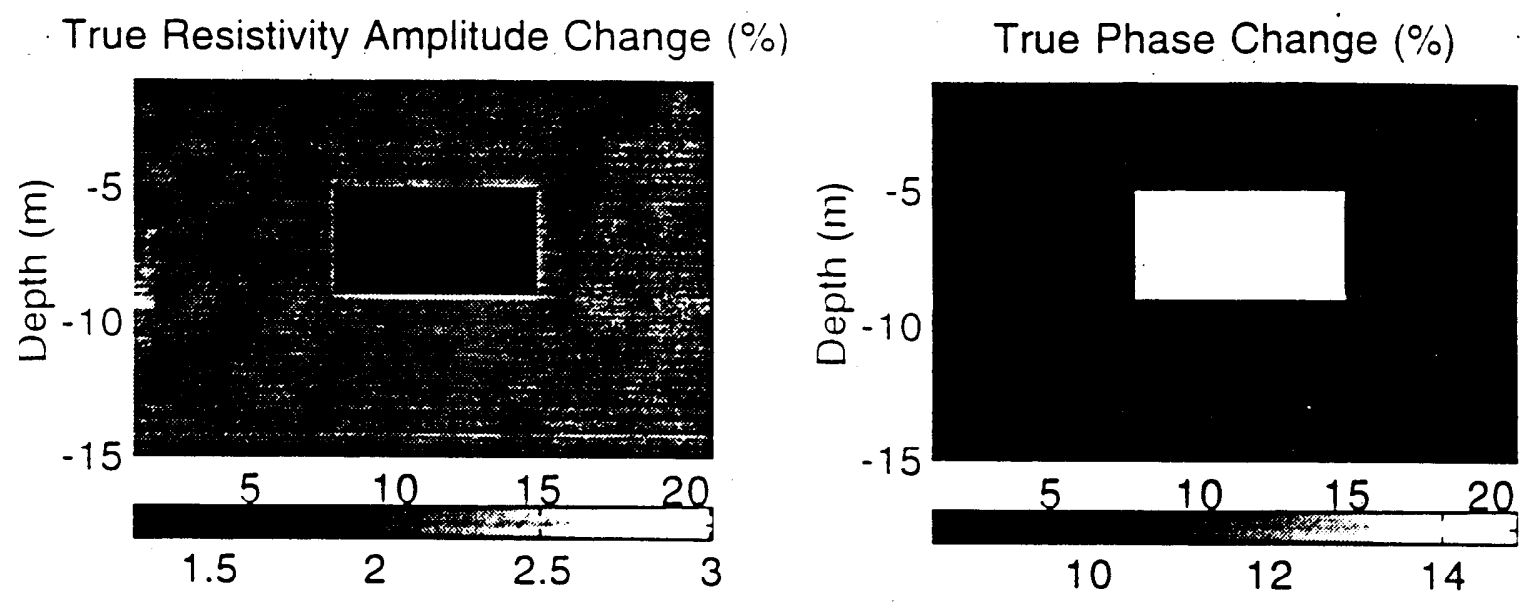

Inverted Resistivity Amplitude Change (\%)
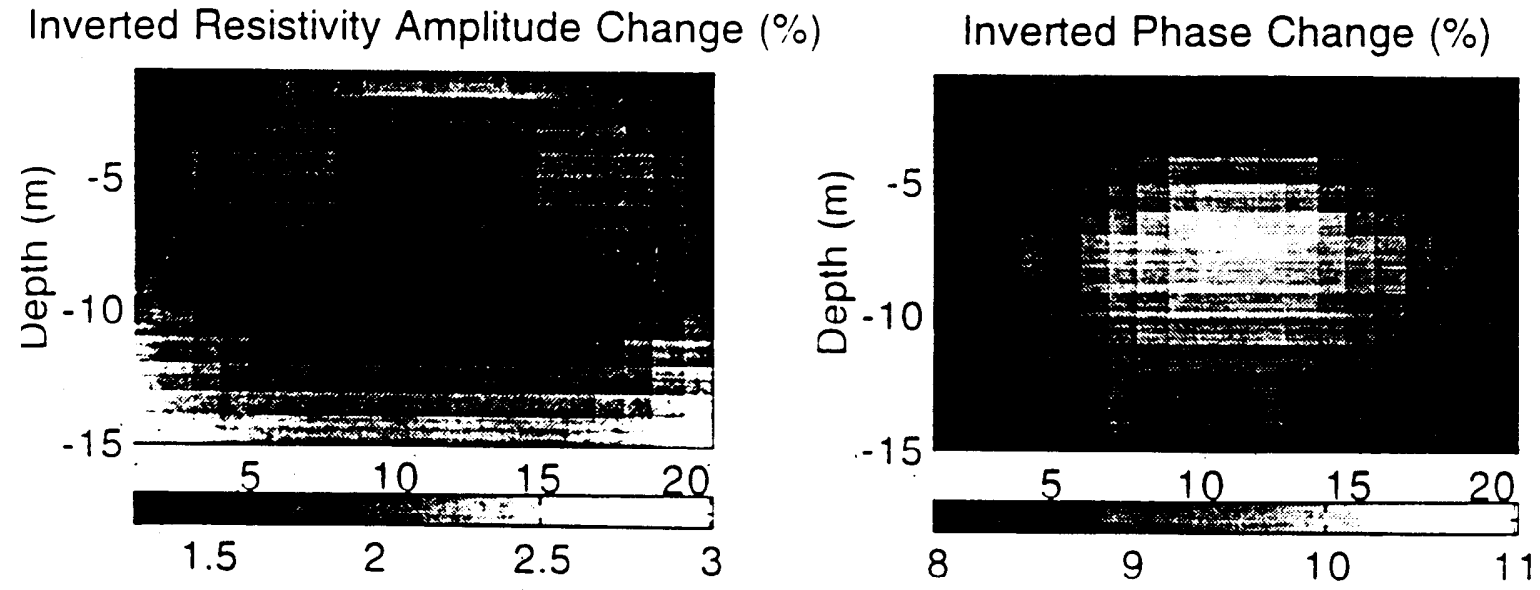

Figure 4. The frequency dependence of the "true" model (top) and the inversion model (bottom) are compared. The amplitude ratio of the resistivity between two frequencies is shown on the left. The phase difference is shown on the right. 